STRUCTURAL SCIENCE CRYSTAL ENGINEERING MATERIALS

ISSN 2052-5206

Received 7 June 2016

Accepted 7 November 2016

Edited by A. A. Pinkerton, University of Toledo, USA

Keywords: bond order; Hirshfeld surface; electrostatic potential.

CCDC reference: 1515490

Supporting information: this article has supporting information at journals.iucr.org/b

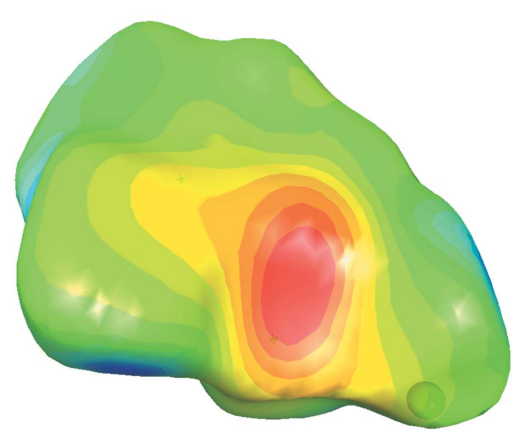

(C) 2017 International Union of Crystallography

\section{Charge density analysis of metformin chloride, a biguanide anti-hyperglycemic agent}

\author{
Rajendran Niranjana Devi, ${ }^{a}$ Christian Jelsch, ${ }^{\mathrm{b} *}$ Samuel Israel, ${ }^{\mathrm{a}}$ Emmanuel Aubert, ${ }^{\mathrm{b}}$ \\ Chellam Anzline $^{\mathrm{a}}$ and Amar A. Hosamanic
}

${ }^{\mathbf{a}}$ Research and Postgraduate Department of Physics, The American College, Madurai 625002, Tamil Nadu, India, ${ }^{\mathbf{b}} \mathrm{CNRS}$ UMR 7036 CRM2, Laboratoire de Cristallographie, Résonance Magnétique et Modélisations, Université de Lorraine, BP 70239, 54506 Vandoeuvre les Nancy CEDEX, France, and 'Solid State and Structural Chemistry Unit, Indian Institute of Science, Bangalore 560012, India. *Correspondence e-mail: christian.jelsch@univ-lorraine.fr

The experimental charge density analysis of the anti-hyperglycemic agent metformin chloride with high-resolution X-ray diffraction data at low temperature $(100 \mathrm{~K})$ has been performed and these experimental results were compared with that derived from the corresponding periodic theoretical calculations at the B3LYP/6-31G** level of theory. The experimental and theoretical multipolar charge-density analyses of metformin chloride have been accomplished in order to understand its structural and electronic properties. The $\mathrm{C}$ and $\mathrm{N}$ atoms of the molecular backbone adopt a near trigonal geometry due to the occurrence of extensive delocalization/resonance of $\mathrm{C}-\mathrm{N}$ bonds, as confirmed by topological analysis and also found by Natural Resonance Theory calculations performed in the isolated metformin cation. The molecule contains six $\mathrm{C}-\mathrm{N}$ bonds and the topological bond order analysis shows that four bonds have bond orders close to $4 / 3$ and two bonds can be considered as single. The analysis of numerical parameters of the valence shell charge concentration reports that the $\mathrm{N} 3$ atom, which forms two bonds with $\mathrm{C}$ atoms, possesses one non-bonding valence-shell charge concentration (VSCC) in the direction of the electron lone pair. Among the intermolecular interactions of the chloride atom with the $\mathrm{H}-\mathrm{C}$ and $\mathrm{H}-\mathrm{N}$ atoms, eight have been found to be shorter than the sum of van der Waals radii. The analysis of contacts on the Hirshfeld surface reveals that the $\mathrm{H}-\mathrm{N} \cdots \mathrm{Cl}$ hydrogen bonds are enriched (over-represented) and act as the driving force in the crystal packing formation. The metformin cations form favorable electrostatic interactions with the chloride anions which have globally a stronger energy than the unfavorable cation/cation interactions.

\section{Introduction}

Type 2 diabetes is one of the most serious medical conditions which affect people drastically and is caused by a combination of lifestyle and genetic factors (Ripsin et al., 2009; Risérus et al., 2009). Its risks are cardiac arrest, neural damage, kidney failure, vision problems which may lead to total blindness, impotency, delayed wound healing leading to toe, feet or leg amputation (Vengateswara et al., 2013). On the whole, diabetes has been reported as the seventh leading cause of death and leading cause of disability in the United States. However, consistent treatment can keep people with diabetes healthy to work and carry out daily activities (Stevens, 2014). Some older medicines such as sulfonylureas, certain alpha-6glucosidase inhibitors, meglitinides and some newer medicines such as thiazolidinediones and dipeptidyl peptidase 4 inhibitors are available on the market to treat type 2 diabetes (Bennett et al., 2011; Meier et al., 2008; van de Laar et al., 2008; Cutler \& Prescott, 2006). 


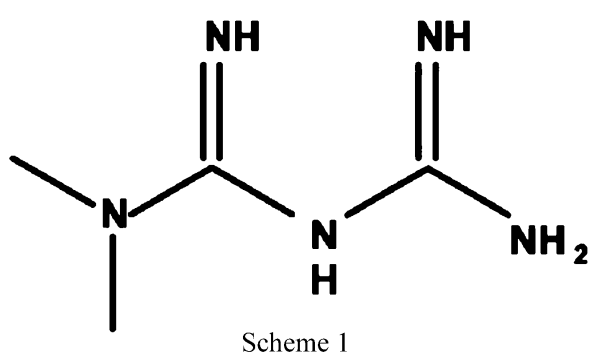

Among them, metformin chloride (MetCl; Scheme 1) has emerged as a superior drug and is widely used in the management of type 2 diabetes (Costa \& Eur, 2001; Satyanarayana et al., 2012). Conjointly, $\mathrm{MetCl}$ is an oral antihyperglycemic agent and a first-line drug for the treatment of type 2 non-insulin-dependent diabetes mellitus (NIDDM; Stepensky et al., 2001) especially for obese and overweight people. The exact action mechanism of metformin is not completely understood. The drug's main effect is to decrease hepatic glucose production and it also increases insulin sensitivity, which increases peripheral glucose uptake. It has been identified that the drug activates the AMP-activated protein kinase (AMPK), and hence has also been prescribed for the treatment of polyps (Shaw et al., 2005). Further investigations of this drug are being conducted in treating other insulin-resistant diseases. Besides that, $\mathrm{MetCl}$ decreases the risk of cardiovascular mortality (Selvin et al., 2008) and at a reasonable dosage does not induce hypoglycemia, for which it has been identified as an anti-hyperglycemic drug (Melchior \& Jaber, 1996). In the light of this information, Stevens (2014) suggests that $\mathrm{MetCl}$ is a drug which compares well over newer medicines such as Januvia and Onglyza. Moreover, on comparison with other biguanides such as phenformin, $\mathrm{MetCl}$ is cheaper, showing fewer side effects (Herrnstadt et al., 1979).

The $\mathrm{MetCl}$ molecule has a peculiar structure; it contains six $\mathrm{C}-\mathrm{N}$ bonds and an $\mathrm{N}$ atom (N3) forming two covalent bonds but not located within a cycle, Therefore, the charge density of the molecule was determined in particular to analyze the resonance/delocalization among the $\mathrm{C}-\mathrm{N}$ bonds, which is reminiscent of what is observed in amides. The $\mathrm{N} 3$ atom with one lone pair in the $\mathrm{C}-\mathrm{N}-\mathrm{C}$ plane can be compared to similar $\mathrm{N}$ atoms in imidazole (Stephen et al., 2011) and pyridine (Rajalakshmi et al., 2014). In order to appreciate the mode of action of a drug, it is also important to afford a precise electrostatic description, which could be beneficial in further investigations such as modeling and docking the drug into binding sites of proteins.

The experimental charge density analysis of $\mathrm{MetCl}$ has been performed from high-resolution single-crystal X-ray diffraction at low temperature $T=100 \mathrm{~K}$. The experimental results were compared with the corresponding theoretical charge density calculations performed using CRYSTAL14 (Dovesi et al., 2014) with the B3LYP/6-31G** method. Topological properties (electron density and its Laplacian), bond-order calculation and electrostatic properties (atomic charge, dipole moment and the electrostatic potential) were elucidated in order to understand the structural, electronic properties of the
Table 1

Experimental details.

\begin{tabular}{|c|c|}
\hline \multicolumn{2}{|l|}{ Crystal data } \\
\hline Chemical formula & $\mathrm{C}_{4} \mathrm{H}_{12} \mathrm{~N}_{5}^{+} \cdot \mathrm{Cl}^{-}$ \\
\hline$M_{\mathrm{r}}$ & 165.64 \\
\hline Crystal system, space group & Monoclinic, $P 2_{1} / c$ \\
\hline Temperature $(\mathrm{K})$ & 100 \\
\hline$a, b, c(\AA)$ & $7.9104(9), 13.8794(17), 7.9310(10)$ \\
\hline$\beta$ & $114.606(6)$ \\
\hline$V\left(\AA^{3}\right)$ & 791.69 (17) \\
\hline$Z$ & 4 \\
\hline Radiation type & Мо $K \alpha$ \\
\hline$\mu\left(\mathrm{mm}^{-1}\right)$ & 0.42 \\
\hline Crystal size $(\mathrm{mm})$ & $0.16 \times 0.10 \times 0.10$ \\
\hline \multicolumn{2}{|l|}{ Data collection } \\
\hline Data collection method & $\omega$ and $\varphi$ scans \\
\hline Diffractometer & Bruker APEXII CCD area detector \\
\hline Absorption correction & Multi-scan \\
\hline$T_{\min }, T_{\max }$ & $0.880,0.949$ \\
\hline $\begin{array}{l}\text { No. of measured, independent and } \\
\text { observed }[I>2 \sigma(I)] \text { reflections }\end{array}$ & $52222,9027,7523$ \\
\hline$R_{\text {int }}, R_{\text {sigma }}$ & $0.0536,0.0344$ \\
\hline$(\sin \theta / \lambda)_{\max }\left(\AA^{-1}\right)$ EXP/THEO & $1.115 / 2.0$ \\
\hline$\Delta \rho_{\max }, \Delta \rho_{\min }\left(\mathrm{e} \AA^{-3}\right)$ & $0.33,-0.33$ \\
\hline \multicolumn{2}{|l|}{ Refinement } \\
\hline No. reflections EXP/THEO & $9029 / 53054$ \\
\hline No. parameters EXP/THEO & $375 / 249$ \\
\hline$R(F) \mathrm{EXP} / \mathrm{THEO}$ & $0.0326 / 0.56$ \\
\hline$w R^{2}(I) \mathrm{EXP} / \mathrm{THEO}$ & $0.0422 / 1.01$ \\
\hline Goodness-of-fit & 0.975 \\
\hline
\end{tabular}

molecule as well. Peculiarly, the characterization of the resonance/delocalization of $\mathrm{C}-\mathrm{N}$ bonds in terms of electron density, Laplacian, bond order and VSCC parameters has been carried out as a specific consideration. On the whole, structural and charge-density information obtained on a molecule in the crystal state yield important information on its electrostatic properties and can contribute to the design of new potential drugs with improved efficiency.

\section{Experimental}

\subsection{Crystallization}

Crystals of $\mathrm{MetCl}$ were grown by slow evaporation from a saturated aqueous solution at room temperature. These crystals were found to be needle shaped. A high quality single crystal was selected for high-resolution X-ray diffraction intensity measurements.

\subsection{X-ray data collection and structure solution}

The crystal was mounted on a Bruker APEX-II CCD diffractometer using a cryo-loop and the measurement was performed at low temperature using a stream of cold nitrogen with the help of an Oxford cryo-system (Cosier \& Glazer, 1986). A high-resolution data set was collected up to $(\sin \theta / \lambda)_{\max }=1.115 \AA^{-1}$, the completeness being $98.2 \%$ at $s=$ $1.115 \AA^{-1}$. The collected data are almost complete at low resolution up to $s<0.7 \AA^{-1}$, with one reflection (10 $\left.\overline{2}\right)$ missing at $s=0.127 \AA^{-1}$; this reflection is presumably overloaded and rejected as it has the strongest $F_{\text {calc }}$ value. 
The refinement of the unit-cell parameters and the data reduction were carried out using SAINT v8.27A software (Bruker, 2012). Absorption correction was performed with the program SADABS2012/1 (Bruker, 2012). Data sorting, scaling and averaging were performed using SORTAV (Blessing, 1997). Molecular graphics have been computed using Olex 2 (Dolomanov et al., 2009) and the structure was solved with the SHELXS (Sheldrick, 2008) structure solution program using direct methods and refined with the SHELXL (Sheldrick, 2008) refinement package using least-squares minimization. Further details of crystal data and measurement conditions are given in Table 1.

\subsection{Refinement details}

2.3.1. Multipolar experimental refinement. The experimental charge density (denoted EXP) was refined against diffraction intensities using MoPro software (Jelsch et al., 2005). The program includes restraints/constraints on the stereochemistry, thermal displacement and charge density parameters and uses the multipolar scattering factor formalism. The multipole expansion was done at the hexadecapolar level for $\mathrm{Cl}$ atoms, the octapole level for $\mathrm{C}$ and $\mathrm{N}$ atoms and dipole level for $\mathrm{H}$ atoms. The core and valence spherical scattering factors were calculated from Su \& Coppens (1997) and the anomalous dispersion coefficients were taken from International Tables for Crystallography (Prince, 2004). For the $\mathrm{H}$ atoms, the $U^{i j}$ parameters were fixed to the values found by the SHADE server (Madsen, 2006). The $\mathrm{H}-X$ distances of $\mathrm{H}$ atoms were restrained to the values obtained from neutron diffraction studies (Allen \& Bruno, 2010) with a restraint sigma of $0.01 \AA$. $X-\mathrm{H}$ distance similarity restraints were also applied to chemically equivalent groups (sigma $=0.01 \AA$ ).

The charge density was subsequently refined against all measured reflection intensities using the multipolar atom model (Hansen \& Coppens, 1978) for pseudo-atom electron density.

The static and deformation maps were computed and plotted using the VMoPro module of the MoPro software (Jelsch et al., 2005) and the molecular view with atomic displacement parameter ellipsoids was produced with MoProViewer (Guillot, 2012).

Automatic restraints of chemical equivalence and local symmetry (Domagała \& Jelsch, 2008) were applied on the electron density parameters such as $\kappa, \kappa^{\prime}$ and $P_{\mathrm{lm}}$ with a sigma of 0.02 . The parameters $\kappa$ and $\kappa^{\prime}$ of $\mathrm{H}$ atoms were restrained to be similar (sigma $=0.03$ ). The $\mathrm{Cl}$ atom was modeled with anharmonic thermal displacement parameters in the order of 3. An extinction coefficient (Becker \& Coppens, 1974) of the diffraction data was refined [isotropic, type 1, Gaussian $E=$ $0.30(3) \times 10^{-4} \mathrm{~s}$ ]. Thermal Diffuse Scattering (TDS) results in errors in the diffraction data with $\Sigma\left(F_{\mathrm{o}}^{2}\right) / \Sigma\left(F_{\mathrm{c}}^{2}\right)$ ratios increasing in the highest resolution shells (Niepötter et al., 2015). Therefore, a degree 3 polynomial scale factor was refined $\left(k=0.132092+0.031410 \times s^{4}\right)$. The application of this correction results in a drop of the $\Sigma\left(F_{\mathrm{o}}^{2}\right) / \Sigma\left(F_{\mathrm{c}}^{2}\right)$ ratio at high resolution from 1.05 to 1.02
The parameters including scale factor, $X Y Z, U^{i j}$, multipoles $P_{\mathrm{lm}}$, valence populations $P_{\text {val }}$, contraction/expansion coefficients $\kappa$ and $\kappa^{\prime}$ were refined successively until convergence. The crystallographic details of the experimental and theoretical refinements are given in Table 1 . The $\Sigma\left(F_{\mathrm{o}}^{2}\right) / \Sigma\left(F_{\mathrm{c}}^{2}\right)$ ratio as a function of resolution is close to unity (Fig. S2); the scatterplot of experimental versus expected $I_{\mathrm{obs}}-I_{\mathrm{calc}}$ values illustrates the very good quality of diffraction data (Fig. S3). The fractal dimension versus residual electron density using all reflections show a symmetric parabolic curve suggesting that the noise in the $I_{h k l}$ data is Gaussian (Fig. S4).

2.3.2. Theoretical structure factor calculation. Periodic quantum mechanical calculations were performed with the program CRYSTAL14 (Dovesi et al., 2014), starting with the crystal geometry observed experimentally. Optimization of $\mathrm{H}$-atom positions, keeping all other atoms and unit-cell parameters fixed, was performed with the density functional theory (DFT) method using the B3LYP hybrid functional completed with dispersion corrections (Grimme, 2006). The 6-31G** basis set was used for all atoms and was taken from the EMSL Basis Set Library (EMSL 1996, 2007).

The five parameters that control the level of accuracy in evaluating the Coulomb and exchange series were set to $I T O L_{i}=8$, for $i=1,4$, and $I T O L_{5}=18$. The shrinking factor of the reciprocal space was set to 4 , corresponding to $80 k$ points in the irreducible Brillouin zone. The periodic wavefunction which is based on the optimized geometry was obtained after convergence of the energy ( $\Delta E \simeq 10^{-8}$ hartree). Structure factors corresponding to the measured diffraction intensities were then calculated up to a resolution of $d=0.25 \AA$ using the theoretical electron density with the option XFAC of the CRYSTAL14 (Dovesi et al., 2014) program. For the $\mathrm{Cl}$ atom, a second basis set 86-311 of Apra et al. (1993) was also tested. The main difference between the two $\mathrm{Cl}$ basis sets used is that the latter offers a richer core and valence electron description, while the former one includes d-type polarization functions. The resulting electron densities and chlorine atomic charge showed no significant differences; therefore, the second basis set is not discussed in the study.

Quantum chemistry calculations were also performed at the B3LYP/6-311G $(\mathrm{d}, \mathrm{p})$ level of theory for the isolated cation in the experimental geometry using GAUSSIAN09 software (Frisch et al., 2009). Subsequent natural bond order and natural resonance theory (Glendening \& Weinhold, 1998) analyses were performed with the NBO6 program (Glendening et al., 2013).

2.3.3. Multipolar theoretical refinement. The THEO multipolar refinement was performed versus the theoretical structure-factor amplitudes $F_{h k l}$. Multipoles were developed up to the hexadecapole level for the $\mathrm{Cl}$ atom, and up to octupole level for $\mathrm{C}$ and $\mathrm{N}$ atoms. For $\mathrm{H}$ atoms, one dipole $\mathrm{Dz}$ and one quadrupole $Q \mathrm{zz}$ oriented along the $X-\mathrm{H}$ axis were refined. Slater functions used for multipoles are given in the supporting information. The multipolar-atom refinement for theoretical structure factors $F_{h k l}$ was performed up to $s=$ 
Table 2

Stereochemistry of $\mathrm{C}$ and $\mathrm{N}$ atoms that are in a trigonal geometry: chiral volume and distance to the plane formed by the three neighbor atoms.

The number in the last column is dimensionless and represents the chiral volume divided by the product of distances between the atom and its three neighbors.

\begin{tabular}{lllll}
\hline Atom & $\begin{array}{l}\text { Distance to } \\
\text { plane }(\AA)\end{array}$ & Plane & $\begin{array}{l}\text { Chiral } \\
\text { volume }\left(\AA^{3}\right)\end{array}$ & $\begin{array}{l}\text { Volume/ } \\
d 1 \times d 2 \times d 3\end{array}$ \\
\hline N1 & 0.060 & $\mathrm{C} 1-\mathrm{C} 2-\mathrm{C} 3$ & 0.311 & 0.110 \\
$\mathrm{~N} 2$ & 0.078 & $\mathrm{C} 3-\mathrm{H} 2 D-\mathrm{H} 2 E$ & 0.251 & 0.182 \\
$\mathrm{~N} 4$ & 0.050 & $\mathrm{C} 4-\mathrm{H} 4 A-\mathrm{H} 4 B$ & 0.163 & 0.118 \\
$\mathrm{~N} 5$ & 0.038 & $\mathrm{C} 4-\mathrm{H} 5 B-\mathrm{H} 5 A$ & 0.124 & 0.090 \\
$\mathrm{C} 3$ & 0.043 & $\mathrm{~N} 1-\mathrm{N} 2-\mathrm{N} 3$ & 0.202 & 0.083 \\
$\mathrm{C} 4$ & 0.023 & $\mathrm{~N} 3-\mathrm{N} 4-\mathrm{N} 5$ & 0.107 & 0.045 \\
\hline
\end{tabular}

$2.0 \AA^{-1}$ reciprocal resolutions following the below options and steps.

(i) The atomic positions were kept fixed to the values obtained from the relaxation geometry.

(ii) The scale factor was fixed to the absolute value (1.0).

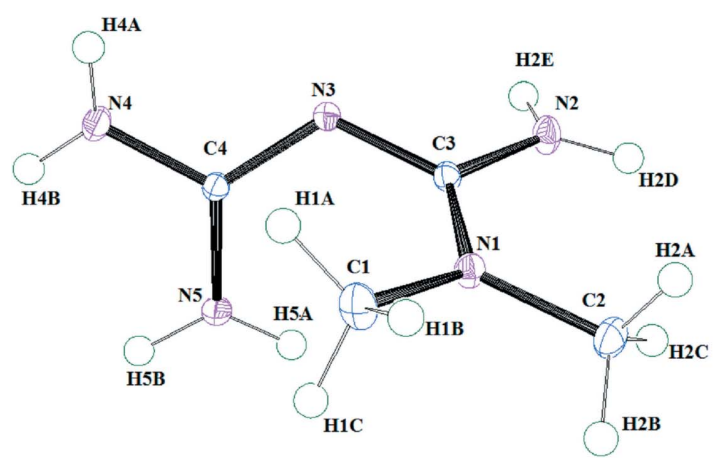

Cl1

Figure 1

ORTEP view of the $\mathrm{MetCl}$ molecule, showing the atom-numbering scheme. Displacement ellipsoids are drawn at the $50 \%$ probability level and $\mathrm{H}$ atoms are shown as small spheres of arbitrary radii. (iii) The atomic thermal motion parameters were set to zero.

(iv) The valence and multipole populations, $\kappa$ and $\kappa^{\prime}$ parameters were refined together with a block diagonal leastsquares normal matrix, until convergence.

(v) The refinement of a kappa parameter for the core electron shell (Overgaard et al., 2011; Farrugia \& Senn, 2012) was applied to non-H atoms to compensate for different functions used in MoPro (Slater) and CRYSTAL14 (Gaussian) to compute the electron density.

The significant residual electron density remaining around the nucleus of the chloride atom was then considerably reduced after kappa-core modeling.

\section{Results and discussion}

\subsection{Structure description}

$\mathrm{MetCl}$ was previously observed to crystallize in two polymorphic forms $A$ and $B$ (Hariharan et al., 1989; Childs et al., 2004), and the most thermodynamically stable phase $A$ was obtained in this work. The two amine groups associated with the $\mathrm{C} 4$ atom are out of the average plane formed by $\mathrm{N} 2-\mathrm{C} 3-$ $\mathrm{N} 4-\mathrm{C} 1$ atoms because of steric repulsion (see ORTEP plot in Fig. 1). The different dihedral angles between these two planes place the $-\mathrm{C}\left(\mathrm{NH}_{2}\right)_{2}$ group of the molecule in approximately opposite directions when the two crystal polymorphs are compared. In form $A$, the $\mathrm{N} 1-\mathrm{C} 3-\mathrm{N} 3-\mathrm{C} 4$ dihedral angle is $53.76^{\circ}$ in this study compared with $53.69^{\circ}$ in the Childs et al. (2004) structure, whereas the angle is $129.06^{\circ}$ in form $B$ (Hariharan et al., 1989). Nearly $2.4 \%$ of unit-cell volume shrinkage takes place in form $A$ when the temperature is decreased from room temperature $(295 \mathrm{~K}$; Hariharan et al., 1989 ) to $100 \mathrm{~K}$ (this study).

As found in the previously reported structures, the bonds to methyl groups $\mathrm{C} 1-\mathrm{N} 1$ and $\mathrm{C} 2-\mathrm{N} 1$ are single bonds having lengths 1.4590 (4) and 1.4565 (5) $\AA$, respectively, which matches well with the standard $\mathrm{C}$ $\mathrm{N}$ length value (1.469 ̊; Allen et al., 1987). For the other $\mathrm{C}-\mathrm{N}$ bonds, the bond distances are in the range 1.333-1.341 $\AA$ and there is some delocalization occurring between the bonds. The bond distances, angles and dihedral angles are given in the supporting information (Tables S1 and S2). The N1 atom is bound to 2 methyl $\mathrm{C}$ atoms ( $\mathrm{C} 1$ and $\mathrm{C} 2$ ) and to the trigonal $\mathrm{C} 3$ atom. The angle $\mathrm{C} 1-$ $\mathrm{N} 1-\mathrm{C} 2$ is found to be $115.12(3)^{\circ}$, which is in between $109.5^{\circ}$ of a tetrahedral geometry and $120^{\circ}$ of a trigonal geometry. The two other $\mathrm{C}-\mathrm{N} 1-\mathrm{C}$ angles are larger than $120^{\circ}\left[\mathrm{C} 3-\mathrm{N} 1-\mathrm{C} 1=122.27(2)^{\circ}\right.$ and $\left.\mathrm{C} 3-\mathrm{N} 1-\mathrm{C} 2=122.06(3)^{\circ}\right]$.
Figure 2

(a) Auto-stereogram showing the crystal packing of $\mathrm{MetCl}$ along the a axis. (b) View along the $\mathbf{b}$ axis. The $\mathrm{Cl} \cdots \mathrm{H}$ and $\mathrm{N} 4 \cdots \mathrm{H} 2 B$ hydrogen bonds are shown once in red.

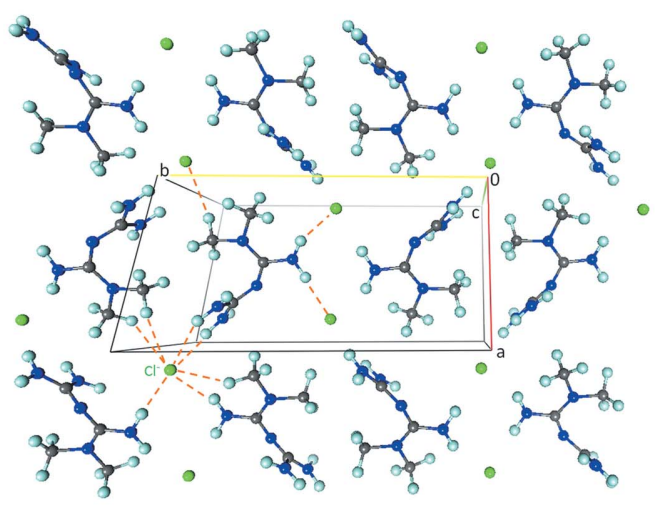

(b) 
The N1 atom is in near trigonal geometry and the larger angles involving the $\mathrm{N} 1-\mathrm{C} 3$ bond are due to the occurrence of delocalization/resonance of double bonds, as in amides (Stewart \& Siddall, 1970; Mujika et al., 2006). The N1, N2, N4 and N5 nitrogen atoms which form three covalent bonds are not fully planar. In order to analyze the geometry of the trigonal $\mathrm{N}$ and $\mathrm{C}$ atoms, the distance to the plane formed by their three neighbors and their respective chiral volumes are given in Table 2. The chiral volume is defined as the volume of the parallelepiped unit cell, whose axes are represented by three bonds (Morrison \& Boyd, 1973). The N5 atom shows the smallest distance to the plane formed by its three neighbors, $d=0.090 \AA$ among the four trigonal $\mathrm{N}$ atoms (Table 2). The $\mathrm{N} 2$ atom is found to be the less planar, as the parallelepiped connected with the three atoms $(\mathrm{C} 3, \mathrm{H} 2 D, \mathrm{H} 2 E)$ has a volume equal to $0.251 \AA^{3}$ and the distance to the neighbors' plane reaches $0.25 \AA$.

\subsection{Packing and interactions}

A view of the $\mathrm{MetCl}$ packing along the a axis is illustrated in Fig. 2(a). The chloride anions are located in shells, close to planes of the equation $y=x+\frac{1}{2}$ or $y=x$. The molecules are arranged in the crystal lattice by 'pairs' of molecules symme-
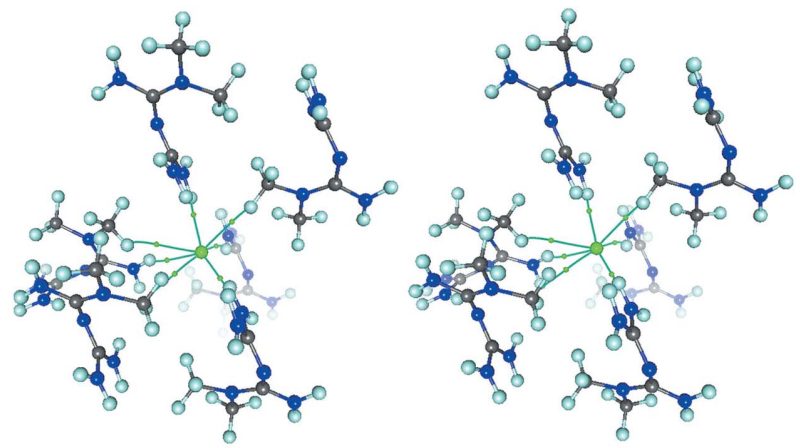

(a)

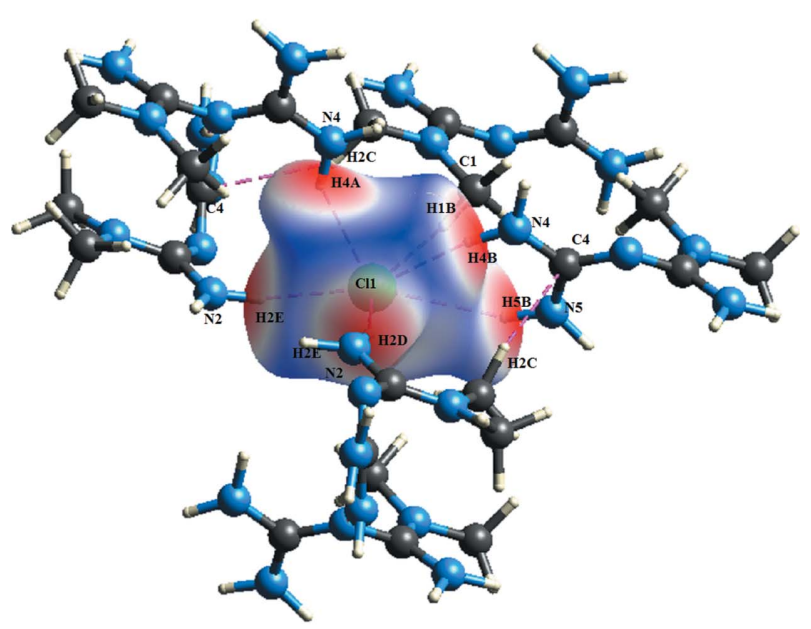

Figure 3

(b)

(a) Stereoview of the chloride anion surrounded by six neighbor cations. The seven topological bond paths and $(3,-1)$ critical points are shown in green. (b) Hirshfeld surface of the $\mathrm{Cl}^{-}$anion with six surrounding cations shown.
Table 3

Hydrogen-bond geometry $\left(\AA{ }^{\circ}\right)$.

\begin{tabular}{|c|c|c|c|c|}
\hline$D-\mathrm{H} \cdots A$ & $D-\mathrm{H}(\AA)$ & $\mathrm{H} \cdots A(\AA)$ & $D \cdots A(\AA)$ & $D-\mathrm{H} \cdots A\left(^{\circ}\right)$ \\
\hline $\mathrm{N} 5-\mathrm{H} 5 B \cdots \mathrm{Cl} 1^{\mathrm{i}}$ & 1.014 & 2.633 & $3.3080(2)$ & 124.0 \\
\hline $\mathrm{N} 4-\mathrm{H} 4 B \cdots \mathrm{Cl} 1^{\mathrm{ii}}$ & 1.014 & 2.237 & $3.2350(4)$ & 167.6 \\
\hline $\mathrm{N} 4-\mathrm{H} 4 A \cdots \mathrm{Cl} 1^{\mathrm{iii}}$ & 1.013 & 2.436 & $3.3104(2)$ & 144.1 \\
\hline $\mathrm{N} 2-\mathrm{H} 2 D \cdots C{ }^{i v}$ & 1.013 & 2.311 & $3.2619(5)$ & 158.8 \\
\hline $\mathrm{N} 2-\mathrm{H} 2 E \cdots \mathrm{Cl} 1^{\mathrm{v}}$ & 1.016 & 2.263 & $3.2619(5)$ & 167.2 \\
\hline $\mathrm{C} 1-\mathrm{H} 1 B \cdots \mathrm{Cl} 1^{\mathrm{vi}}$ & 1.076 & 2.760 & $3.7932(6)$ & 160.7 \\
\hline $\mathrm{N} 5-\mathrm{H} 5 B \cdots \mathrm{Cl} 1^{\mathrm{vii}}$ & 1.014 & 2.823 & $3.6588(5)$ & 140.0 \\
\hline $\mathrm{N} 5-\mathrm{H} 5 A \cdots \mathrm{N} 3^{\mathrm{viii}}$ & 1.014 & 1.948 & $2.9556(4)$ & 171.8 \\
\hline
\end{tabular}

Symmetry codes: (i) $\quad-x+1, y-\frac{1}{2},-z+\frac{1}{2}$; (ii) $\quad x-1,-y+\frac{3}{2}, z-\frac{1}{2}$; $-x+1, y-\frac{1}{2},-z+\frac{3}{2}$; (iv) $x, y, z$; (v) $-x+1,-y+1,-z+1$; (vi) $-x, y-\frac{1}{2},-z+\frac{1}{2}$; (vii) $x-1,-y+\frac{3}{2}, z-\frac{1}{2}$; (viii) $x,-y+\frac{3}{2}, z+\frac{1}{2}$.

trically related by a center of inversion $1-x, 1-y, 1-z$, which can be seen in Fig. 2(b). The head-to-head arrangement is maintained by electrostatic interactions of the two $\mathrm{NH}_{2}$ groups with two chloride anions. The $\mathrm{C} 1$ methyl group interacts with itself through symmetry with an inversion center, which can also be observed in Fig. 2(b).

The crystal packing includes ionic and hydrogen bonding and $\pi \cdots \pi$ stacking. The packing is mainly stabilized by $\mathrm{N}-$ $\mathrm{H} \cdots \mathrm{N}$ and $\mathrm{N}-\mathrm{H}^{\delta+} \cdots \mathrm{Cl}^{-}$contacts. Interestingly, the $\mathrm{Cl} 1$ atom has eight intermolecular $(\mathrm{C}, \mathrm{N})-\mathrm{H} \cdots \mathrm{Cl}$ contacts shorter than the sum of van der Waals radii $(1.75+1.20 \AA)$ with six different neighboring molecules (Fig. $3 a$ ). The conventional $\mathrm{N}-\mathrm{H} \cdots \mathrm{N}$ contact is found once $(\mathrm{H} 5 A \cdots \mathrm{N} 3)$, involving a strong hydrogen-bond donor and acceptor. The hydrogenbonding parameters are given in Table 3 .

One of the best ways to explore and visualize the intermolecular interactions is the Hirshfeld surface analysis (McKinnon et al., 2004; Spackman \& Byrom, 1997). Fig. 3(b) clearly shows the contacts of hydrogen-bond donors and acceptors and the red color indicates the region where the intermolecular distance between two atoms is shorter than the sum of their van der Waals radii.

The values of $d_{\mathrm{i}}$ and $d_{\mathrm{e}}$ at the Hirshfeld surface points are plotted against each other to generate the so-called fingerprint plot (Fig. 4a; Spackman, 2002) through which the different interaction types such as hydrogen bonding, van der Waals contacts, $\mathrm{C}-\mathrm{H} \cdots \pi$ and $\pi \cdots \pi$ stacking can be identified. As seen in many of the organic structures (Chęcińska et al., 2011), the $\mathrm{H} \cdot \mathrm{H}$ contacts $(54.3 \%)$ are predominant (Figs. $4 b$ and $c$ ) in the $\mathrm{MetCl}$ crystal. Hydrogen-hydrogen bonding has been found to be a stabilizing interaction in molecules and crystals (Matta et al., 2003). H..H contacts are very common and generally display the shortest contact distances on the surface due to the small van der Waals radius of hydrogen. The closest contacts give rise to the typical long spikes in the top-left and the bottom-right corners in the fingerprint and are due to the $\mathrm{Cl} \cdots \mathrm{H} / \mathrm{H} \cdots \mathrm{Cl}$ interactions (26.9\%; Fig. $4 c$ ).

The enrichment ratio descriptor proposed by Jelsch et al. (2014) in the analysis of the contacts in molecular crystals is shown in Table 4. An enrichment ratio $E_{X Y}$ larger than unity indicates an enhanced propensity of pairs of chemical species $X \cdots Y$ to form interactions (given the chemical composition on the Hirshfeld surface, the actual contact proportion is 
higher than if all contacts were equiprobable). The charged $\mathrm{Hn}$ and less polar $\mathrm{Hc}$ hydrogen atoms, linked to $\mathrm{N}$ and $\mathrm{C}$, respectively, have been distinguished as they have very different interaction properties (Table 4). The list of $E$ ratios spotlights the highly enriched $\mathrm{Hn} \cdots \mathrm{Cl}$ contact $(E=2.32)$, which can be considered as the most favored contact. The

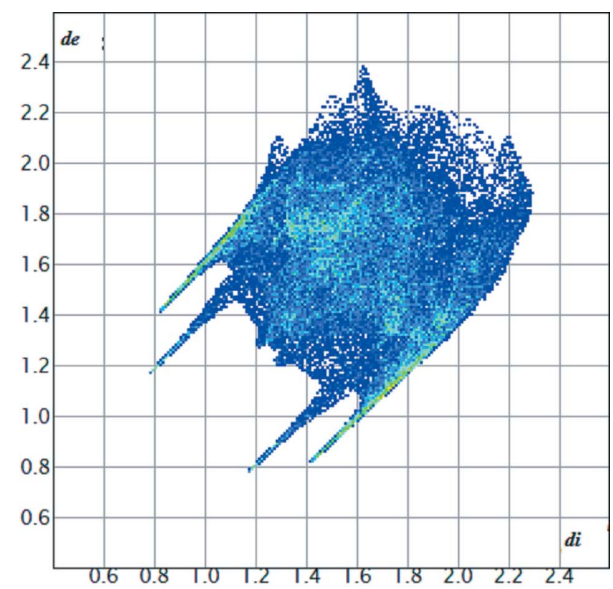

(a)

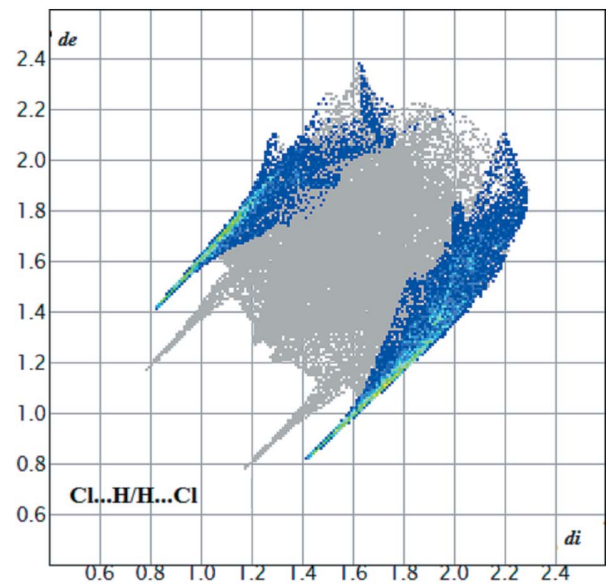

(b)

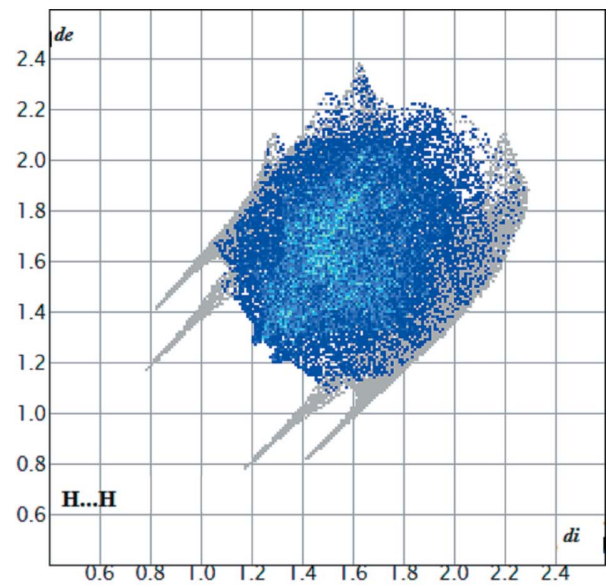

(c)

Figure 4

Fingerprint plots: $(a)$ full, $(b)$ resolved into $\mathrm{H} \cdots \mathrm{H}$ and $(c) \mathrm{Cl} \cdots \mathrm{H} / \mathrm{H} \cdots \mathrm{Cl}$ contacts, showing the percentages of contact contributing to the total Hirshfeld surface area of $\mathrm{MetCl}$ in the crystal.
Table 4

Nature of contacts at the Hirshfeld surface and enrichment ratios.

The second row shows the chemical content on the surface. The next five lines show $C_{X Y}$, the $\%$ of $X-Y$ contacts, while the last five last lines show the enrichment ratios $E_{X Y}$. The enrichment values larger than unity are in bold and highlight enhanced interactions.

\begin{tabular}{llllll}
\hline Atom & $\mathrm{Cl}$ & $\mathrm{Hn}$ & $\mathrm{C}$ & $\mathrm{N}$ & $\mathrm{Hc}$ \\
\hline Surface $(\%)$ & 19.4 & 31.5 & 8.0 & 12.3 & 28.9 \\
\hline $\mathrm{Cl}$ & 0.1 & 30.4 & 0.3 & 0.6 & 7.9 \\
$\mathrm{Hn}$ & & 5.2 & 2.1 & 6.6 & 12.2 \\
$\mathrm{C}$ & & 1.3 & 3.7 & 6.9 \\
$\mathrm{~N}$ & Contacts $(\%)$ & & 0.7 & 11.0 \\
$\mathrm{Hc}$ & & & & 10.7 \\
$\mathrm{Cl}$ & & & & & \\
$\mathrm{Hn}$ & 0.04 & $\mathbf{2 . 3 2}$ & 0.1 & 0.13 & 0.89 \\
$\mathrm{C}$ & & 0.54 & 0.44 & 0.92 & 0.7 \\
$\mathrm{~N}$ & & & $\mathbf{2 . 1 7}$ & $\mathbf{2 . 0 2}$ & $\mathbf{1 . 5 4}$ \\
$\mathrm{Hc}$ & Enrichment & & & 0.49 & $\mathbf{1 . 6 7}$ \\
\hline
\end{tabular}

$\mathrm{Hn} \cdots \mathrm{Cl}^{-}$hydrogen bonds are presumably the driving force in the crystal packing formation as they are enriched and represent the interaction with the highest surface $30.4 \%$ among all contacts (if $\mathrm{Hc}$ and $\mathrm{Hn}$ are distinguished). Moreover, all other contacts involving $\mathrm{Cl}^{-}$and $\mathrm{Hn}$ are impoverished. The contacts $\mathrm{N} \cdots \mathrm{Cl}, \mathrm{C} \cdots \mathrm{N}, \mathrm{Cl} \cdots \mathrm{Cl}$ are strongly avoided in the crystal as they have very low values of enrichment ratios, $E_{\mathrm{NCl}}=0.13, E_{\mathrm{CCl}}=0.10$ and $E_{\mathrm{ClCl}}=0.04$, respectively. The contacts between the chloride anion and the low positively charged $\mathrm{Hc}$ atoms represent more than $10 \%$ of the contact surface. The $\mathrm{Cl} \cdots \mathrm{Hc}$ weak hydrogen bonds are still favorable from an electrostatic point of view, but much less than $\mathrm{Cl} \cdots \mathrm{Hn}$ and are slightly impoverished $(E=0.89)$ in the present crystal structure.

There are two $\pi \cdots \pi$ stacking contact types, namely of C $\cdots \mathrm{C}$ and $\mathrm{C} \cdots \mathrm{N}$, which have high enrichment ratios, $E_{\mathrm{CC}}=$ 2.17 and $E_{\mathrm{CN}}=2.02$. These interactions are found to be favored despite their low interaction surface, 1.3 and $3.7 \%$,

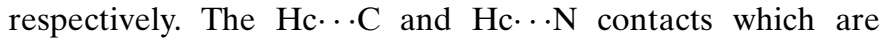
$\mathrm{H} \cdots \pi$ type of interactions also play an important role with a contribution to the interacting surface larger than $6.9 \%$ and enrichment ratios larger than 1.5. Self-contacts between charged species $\left(\mathrm{Cl}^{-}, \mathrm{Hn}, \mathrm{N}\right)$ are disfavored as electrostatically unfavorable, while the hydrophobic contacts $\mathrm{C} \cdots \mathrm{C}$ and $\mathrm{Hc} \cdots \mathrm{Hc}$ are more favored (notably $E_{\mathrm{CC}}=2.17$ ).

\subsection{Topology of the covalent bonds}

An investigation using Hansen-Coppens model for highresolution X-ray data collected at $100 \mathrm{~K}$ is highly essential in order to gain insight into the electronic properties of MetCl. The high quality of the XRD and the efficiency of the multipolar modeling are authenticated by the residual density map (shown in Fig. S1) which has the absence of significant and systematic electron density peaks on the covalent bonds and on the atom sites. Both the experimental and theoretical deformation density maps $\Delta \rho(\mathbf{r})$ show the bonding features of atoms (Figs. $5 a-d$ ) and specifically the lone pair of the N3 atom 


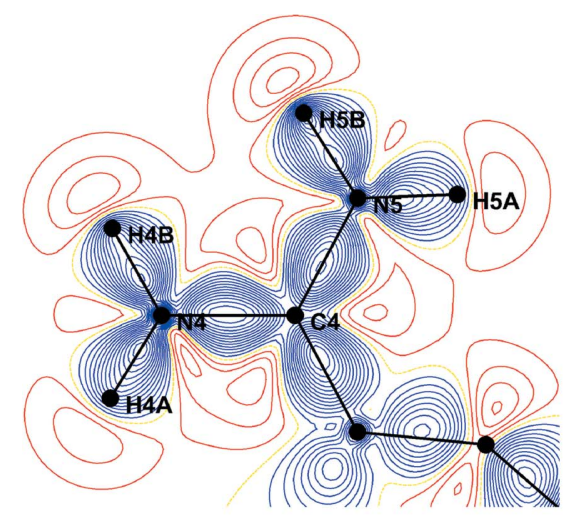

(a)

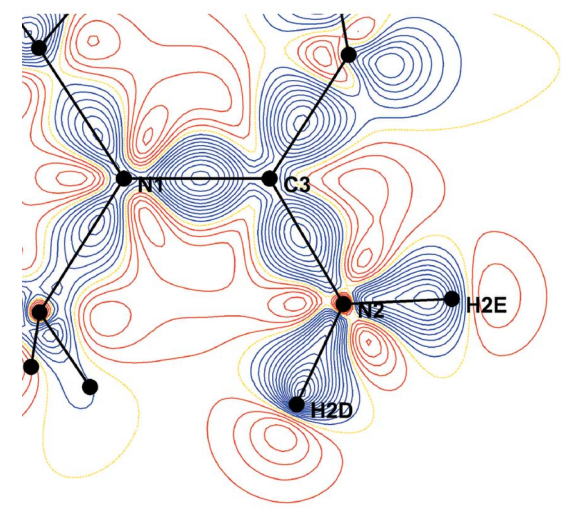

(d)

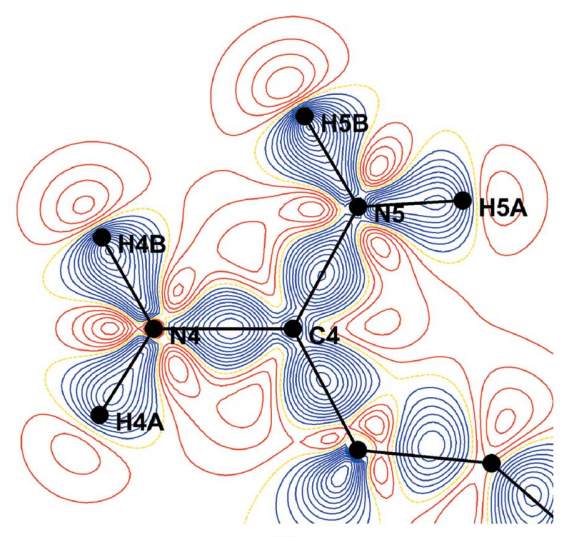

(b)

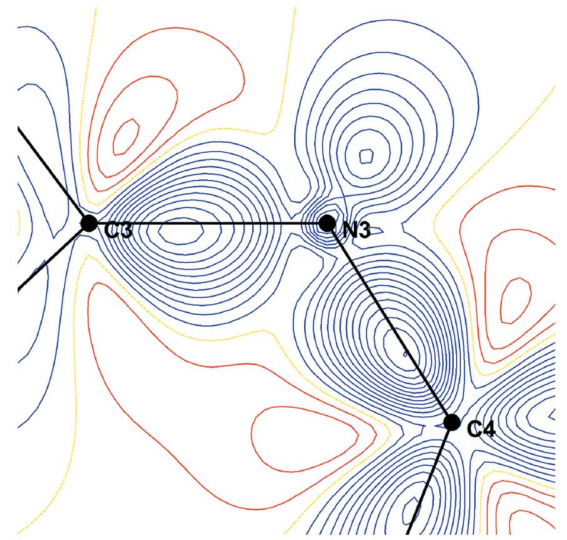

(e)

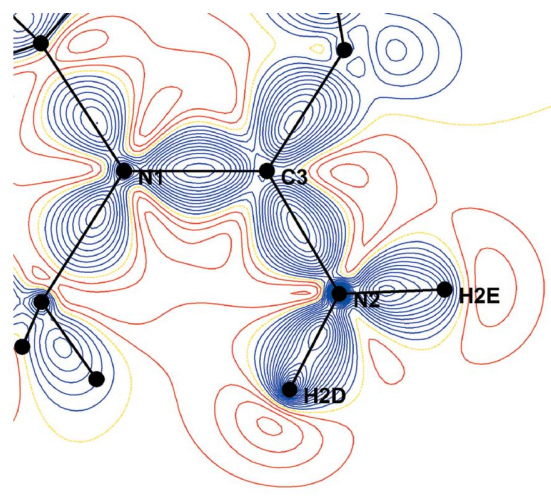

(c)

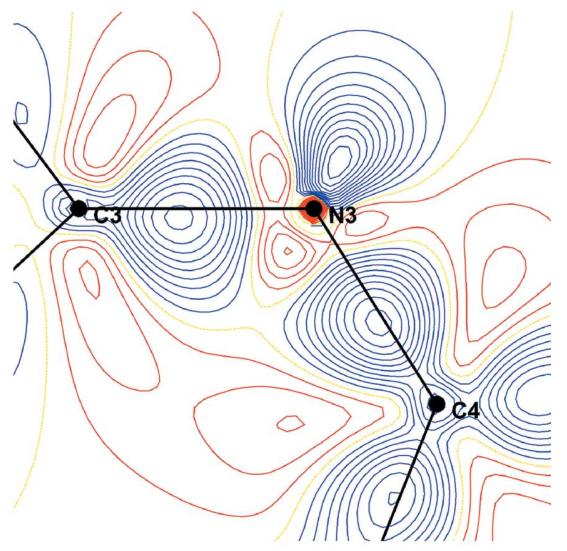

$(f)$

Figure 5

Deformation electron density map for various planes of MetCl. (a) N4-C4-N5 (EXP); (b) N4-C4-N5 (THEO); (c) N1-C3-N2 (EXP); (d) N1$\mathrm{C} 3-\mathrm{N} 2$ (THEO); (e) $\mathrm{C} 3-\mathrm{N} 3-\mathrm{C} 4(\mathrm{EXP}) ;(f) \mathrm{C} 3-\mathrm{N} 3-\mathrm{C} 4$ (THEO). Contour intervals are 0.05 e $\AA^{-3}$; blue lines represent positive contours, red lines are negative contours and the yellow lines are zero contours.

(Figs. $5 e$ and $f$ ). The three-dimensional $\Delta \rho(\mathbf{r})$ map provides a good description of the aspherical nature of the charge density distribution around all the atoms (Fig. 6). The topological parameters for the $(3,-1)$ bond critical points $(\mathrm{CP})$ are listed in Table S4 and confirm the covalent sharing of atoms in the molecule (Fig. 7). The $\rho\left(\mathbf{r}_{\mathrm{cp}}\right)$ values of the $\mathrm{C}-\mathrm{N}$ bonds lie in

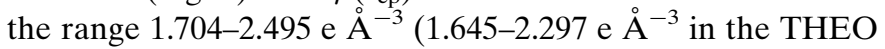
charge density) and are comparable with alike bonds seen in the molecules GlyThr and imidazole (Benabicha et al., 2000; Stephen et al., 2011). The bond order defines the number of electron pairs shared between two bonded atoms and is mainly related to orbital representations (Mayer et al., 2004). The $\mathrm{C} 1-\mathrm{N} 1$ and $\mathrm{C} 2-\mathrm{N} 1$ bonds, involving the two methyl groups, appear as single bonds as their bond orders (computed for a cation in vacuo) are smaller than unity (Table 5). All other $\mathrm{C}-\mathrm{N}$ bonds have their bond order (see Table 5) in the 1.281.47 range, which enunciates the occurrence of $\pi$-delocalization of the $\mathrm{C}-\mathrm{N}$ bonds. The resonance structures of the isolated MET cation within the NBO framework are shown in Fig. S5.

$\mathrm{C} 4-\mathrm{N} 3$ is the shortest $\mathrm{C}-\mathrm{N}$ covalent bond (Table 5) and has the highest bond order. Bond orders derived from the topological parameters and HOMED index are further discussed in the supporting information.
Remarkably, the N3 atom has two neighbors and the angle $\mathrm{C} 4-\mathrm{N} 3-\mathrm{C} 3$ is $122.08(3)^{\circ}$ and the three neighbors $(\mathrm{C} 3, \mathrm{C} 4$, $\mathrm{Lp}$ ) are in a trigonal planar geometry. The sum of the two $\mathrm{C}-$ $\mathrm{N}$ bond orders on the $\mathrm{N} 3$ atom reaches 2.82 and the topological CP ellipticities are larger than 0.15 as the N3 atom displays $s p^{2}$ hybridization. The N3 atom has a lone pair as in the cases of non-protonated nitrogen atoms found in planar

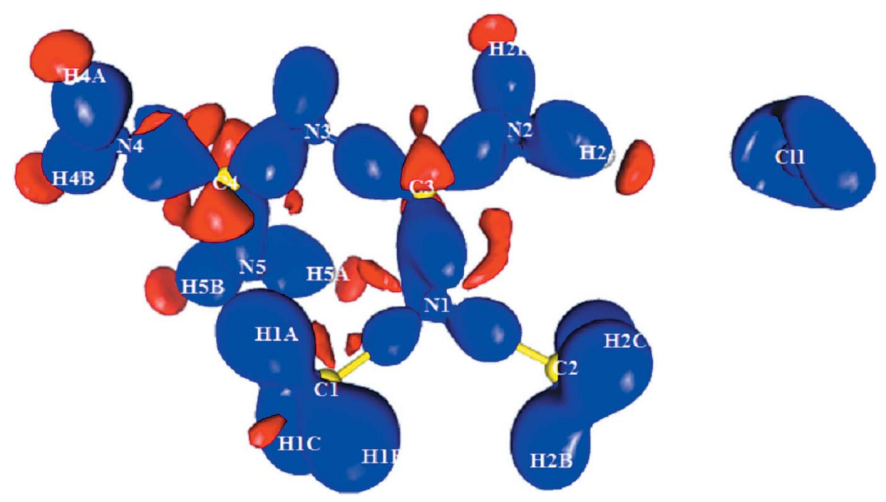

Figure 6

Three-dimensional static deformation density maps of MetCl. The isosurfaces are drawn at intervals of $0.05 \mathrm{e} \AA^{-3}$. Positive and negative values are represented in blue and red, respectively. 


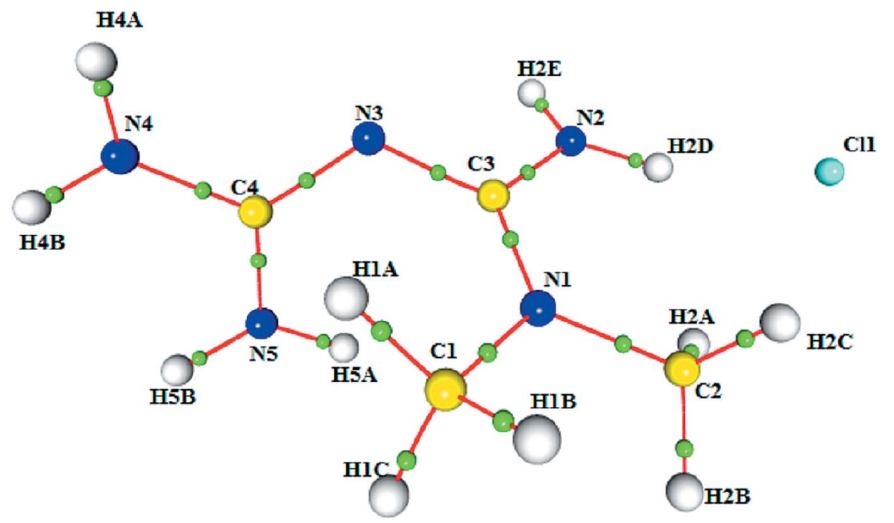

Figure 7

The molecular graph showing the critical points of MetCl. The (large) circles represent the atomic positions, green small circles represent $(3,-1)$ covalent bond critical points. Bond paths are denoted in red lines.

cycles such as imidazole (Stephen et al., 2011) and pyridine (Rajalakshmi et al., 2014).
In all $\mathrm{C}-\mathrm{N}$ bonds, $\mathrm{BCPs}$ are closer to the $\mathrm{C}$ atom than to the $\mathrm{N}$ atoms (Fig. 8). This is due to the additive effects of the stronger electronegativity and of the larger van der Waals radius of the $\mathrm{N}$ atoms compared with $\mathrm{C}$ atoms. Moreover, all $\mathrm{C}-\mathrm{N}$ bonds except those involving the methyl groups have their ellipticity values above 0.15 , establishing their partial $\pi$ character.

Analysis of the numerical parameters at the $(3,-3)$ CPs (maxima) of $L(\mathbf{r})$ has been carried out to gain insight into the prominence of the valence-shell charge concentration (VSCC) in the bonding directions of the $\mathrm{N}$ atoms (Table 6). Around each atom, three VSCCs were found. All N atoms, except N3, form three covalent bonds and display three corresponding VSCCs in the directions of the bonds. The N3 atom, which forms only two covalent bonds, has one non-bonded concentration in the direction of the lone pair. Interestingly, the VSCCs of the N3 atom are almost equal in the directions of $\mathrm{C} 3$

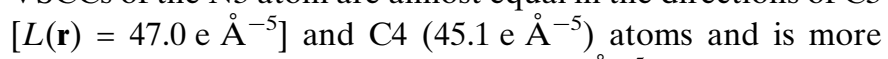

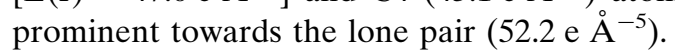

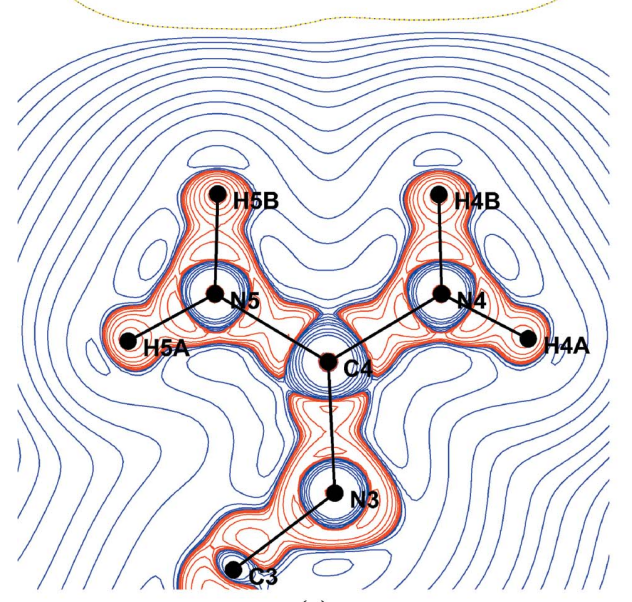

(a)

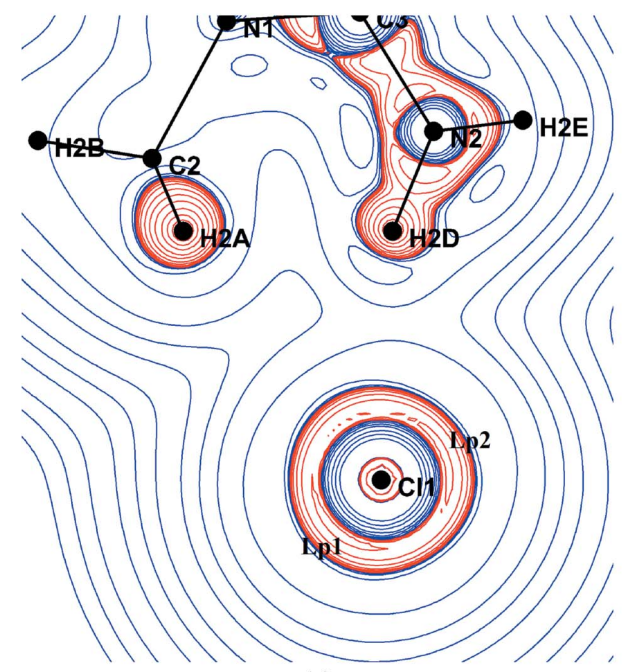

(c)

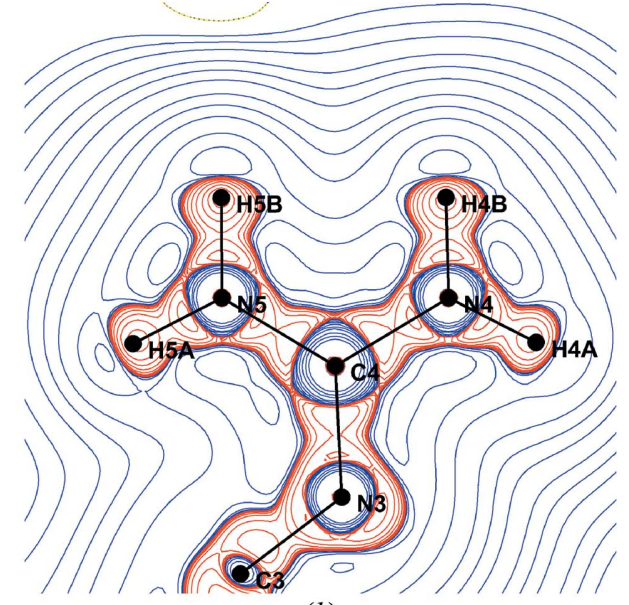

(b)

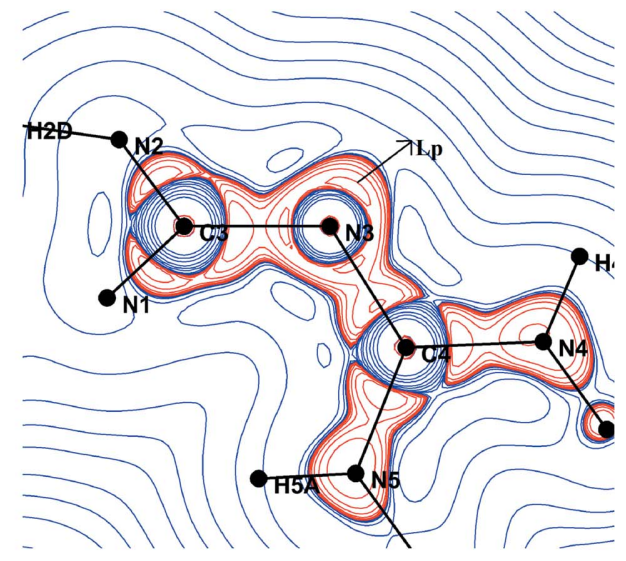

(d)

Figure 8

Laplacian of the electron density in the N5-C4-N3-N4 plane. (a) Experimental and $(b)$ theoretical map; (c) lone pairs of the $\mathrm{Cl}^{-}$anion and $(d)$ lone pair of the $\mathrm{N} 3$ atom in the $\mathrm{C} 3-\mathrm{N} 3-\mathrm{C} 4$ plane. $(c)$ and $(d)$ are experimental. Solid blue and red lines represent the positive and negative contour lines, respectively. Contour levels $2,4,8,10^{\mathrm{n}}, n=-1,0,1$.

\subsection{Atomic charges}

Atomic charges integrated over the respective atomic basins are in good agreement with the chemical nature of atoms in the $\mathrm{MetCl}$ molecule. Importantly, the negative charges are carried by N1, N2, N3, N4, N5 and Cl1 atoms among which the $\mathrm{N} 4$ atom attached to two $\mathrm{H}$ atoms exhibits the most negative charge (EXP -1.192e, THEO $-1.12 \mathrm{e}$ ) in the molecule (Table 7). The charge of the electron cloud seen on the N3 atom is comparatively lower (EXP $-0.959 \mathrm{e}$, THEO $-1.017 \mathrm{e}$ ) since it is not connected to any $\mathrm{H}$ atom. As the two methyl groups, $\mathrm{CH}_{3}(\mathrm{C} 1)$ and $\mathrm{CH}_{3}(\mathrm{C} 2)$, have electron-donating capacity, they indeed possess globally positive charges. The global EXP charges of the two methyl groups are similar [0.435e for $\mathrm{CH}_{3}(\mathrm{C} 1)$ and $0.453 \mathrm{e}$ for $\left.\mathrm{CH}_{3}(\mathrm{C} 2)\right]$. These charges are higher than the theoretically calculated values: $0.372 \mathrm{e}$ for $\mathrm{CH}_{3}(\mathrm{C} 1)$ and 0.329 e for $\mathrm{CH}_{3}(\mathrm{C} 2)$.

As expected, the electron accepting capacity is highest for the three $-\mathrm{NH}_{2}$ groups which have negative charges around $-0.23 \mathrm{e}$ (Table 7). The C3 and C4 atoms which are each attached to two receiving $-\mathrm{NH}_{2}$ groups and to the $\mathrm{N} 3$ atom with a lone pair have the highest positive charges in the 
Table 5

Bond orders and topological properties of the $\mathrm{C}-\mathrm{N}$ bonds.

Bond order is obtained from molecular orbital analysis (Bridgeman et al., 2001; Mayer et al., 2004) in the isolated metformin cation. The second line corresponds to the theoretical model. Statistical errors on topological properties can be obtained by computing the sample standard deviations (s.s.d.) from a number of structures (e.g. $N=20)$ at the standard deviation from the final model (Jelsch et al., 2017). To give an idea of the magnitude of the uncertainties, the s.s.d. values are shown, for instance, for the $\mathrm{C} 3-\mathrm{N} 2$ bond.

\begin{tabular}{|c|c|c|c|c|c|}
\hline Bond & $n_{\text {Mayer }}$ & Length $(\AA)$ & $\begin{array}{l}\rho_{\mathrm{CP}}\left(\mathbf{r}_{\mathrm{cp}}\right) \\
\left(\mathrm{e} \AA^{-3}\right)\end{array}$ & $\begin{array}{l}L\left(\mathbf{r}_{\mathrm{cp}}\right) \\
\left(\mathrm{e} \AA^{-5}\right)\end{array}$ & Ellipticity $\epsilon$ \\
\hline \multirow[t]{2}{*}{$\mathrm{C} 1-\mathrm{N} 1$} & 0.92 & $1.4590(4)$ & 1.704 & 10.8 & 0.04 \\
\hline & & & 1.645 & 6.9 & 0.07 \\
\hline \multirow{2}{*}{$\mathrm{C} 2-\mathrm{N} 1$} & 0.93 & $1.4566(5)$ & 1.742 & 11.1 & 0.09 \\
\hline & & & 1.671 & 7.2 & 0.08 \\
\hline \multirow[t]{2}{*}{$\mathrm{C} 3-\mathrm{N} 1$} & 1.28 & $1.3376(4)$ & 2.361 & 25.1 & 0.26 \\
\hline & & & 2.296 & 27.3 & 0.22 \\
\hline \multirow[t]{3}{*}{$\mathrm{C} 3-\mathrm{N} 2$ s.s.d. } & 1.26 & $1.3372(4)$ & 2.375 & 25.4 & 0.25 \\
\hline & & & 2.275 & 24.8 & 0.23 \\
\hline & & & 0.024 & 1.1 & 0.027 \\
\hline \multirow[t]{2}{*}{$\mathrm{C} 3-\mathrm{N} 3$} & 1.35 & $1.3545(4)$ & 2.307 & 20.4 & 0.15 \\
\hline & & & 2.205 & 21.2 & 0.15 \\
\hline \multirow[t]{2}{*}{$\mathrm{C} 4-\mathrm{N} 3$} & 1.47 & $1.3332(3)$ & 2.495 & 24.6 & 0.21 \\
\hline & & & 2.324 & 26.6 & 0.18 \\
\hline \multirow[t]{2}{*}{$\mathrm{C} 4-\mathrm{N} 4$} & 1.24 & 1.3407 (4) & 2.420 & 29.4 & 0.24 \\
\hline & & & 2.277 & 25.8 & 0.24 \\
\hline \multirow[t]{2}{*}{$\mathrm{C} 4-\mathrm{N} 5$} & 1.21 & $1.3398(3)$ & 2.451 & 27.4 & 0.24 \\
\hline & & & 2.297 & 25.6 & 0.24 \\
\hline
\end{tabular}

Table 6

Valence shell charge concentrations (VSCC) around N1, N2, N3, N4 and $\mathrm{N} 5$ atoms, at the $(3,-3)$ Laplacian CPs: Laplacian and electron density.

$\mathrm{Lp}_{y}$ denotes the respective electron lone pair at atom $Y$.

\begin{tabular}{llll}
\hline Atom & Direction & $L(\mathbf{r})\left(\mathrm{e} \AA^{-5}\right)$ & $\rho(\mathbf{r})\left(\mathrm{e}^{-3}\right)$ \\
\hline N1 & C1 & 56 & 3.42 \\
& C2 & 56 & 3.53 \\
N2 & C3 & 54.9 & 3.64 \\
& C3 & 57.3 & 3.91 \\
& H2D & 71 & 3.79 \\
N3 & H2E & 68.1 & 3.73 \\
& C3 & 47 & 3.47 \\
& C4 & 45.1 & 3.51 \\
N4 & Lp(N3) & 52.2 & 3.29 \\
& C4 & 62.8 & 3.75 \\
& H4 $A$ & 78 & 3.9 \\
N5 & H4 $B$ & 74.6 & 3.84 \\
& C4 & 55.2 & 3.63 \\
& H5 $A$ & 71.7 & 3.79 \\
& H5 $B$ & 72.5 & 3.82 \\
\hline
\end{tabular}

molecule. The most positive charge (EXP $+1.294 \mathrm{e}$, THEO $+1.474 \mathrm{e}$ ) is exhibited by the $\mathrm{C} 4$ atom. The $\mathrm{C} 3$ atom, which is bonded to the three negatively charged N1, N2 and N3 atoms, exhibits the second highest positive charge $(\mathrm{EXP}+1.203 \mathrm{e}$, THEO +1.307e). The central molecular skeleton $\mathrm{C} 4-\mathrm{N} 3-$ C3-N1 exhibits a global positive charge. On the whole, the two methyl groups as well as the $\mathrm{C} 3$ and $\mathrm{C} 4$ atoms take responsibility for the cationic character of metformin. All C$\mathrm{N}$ bonds are polarized as observed in the deformation electron density maps where the bonding density is closest to the $\mathrm{N}$ atoms (Fig. 5). Notably, the bond $\mathrm{C} 4-\mathrm{N} 4$ formed by the most electronegative $\mathrm{N} 4$ atom $(-1.192 \mathrm{e})$ and the most positive $\mathrm{C} 4$ atom $(1.294 \mathrm{e})$ is the most polarized in the molecule.
Table 7

Bader atomic charges (e) of MetCl.

The charges of selected groups of atoms are also shown.

\begin{tabular}{|c|c|c|c|c|c|}
\hline Atoms & $Q_{\text {exp }}$ & $Q_{\text {theo }}$ & Atoms/group & $Q_{\text {exp }}$ & $Q_{\text {theo }}$ \\
\hline $\mathrm{C} 1$ & 0.099 & 0.296 & $\mathrm{Cl} 1$ & -0.701 & -0.675 \\
\hline $\mathrm{C} 2$ & -0.015 & 0.364 & N1 & -1.013 & -0.902 \\
\hline $\mathrm{C} 3$ & 1.204 & 1.307 & $\mathrm{~N} 2$ & -1.151 & -0.99 \\
\hline $\mathrm{C} 4$ & 1.294 & 1.474 & N3 & -0.959 & -1.017 \\
\hline $\mathrm{H} 1 A$ & 0.112 & -0.072 & N4 & -1.192 & -1.12 \\
\hline $\mathrm{H} 1 B$ & 0.101 & 0.109 & N5 & -1.189 & -1.072 \\
\hline $\mathrm{H} 1 C$ & 0.123 & 0.039 & & & \\
\hline $\mathrm{H} 2 A$ & 0.152 & -0.01 & & & \\
\hline $\mathrm{H} 2 B$ & 0.141 & -0.066 & & & \\
\hline $\mathrm{H} 2 \mathrm{C}$ & 0.175 & 0.041 & & & \\
\hline $\mathrm{H} 2 D$ & 0.472 & 0.318 & $\mathrm{CH}_{3}(\mathrm{C} 2)$ & 0.453 & 0.329 \\
\hline $\mathrm{H} 2 E$ & 0.447 & 0.336 & $\mathrm{CH}_{3}(\mathrm{C} 1)$ & 0.435 & 0.372 \\
\hline $\mathrm{H} 4 A$ & 0.467 & 0.4 & $\mathrm{NH}_{2}(\mathrm{~N} 2)$ & -0.232 & -0.336 \\
\hline $\mathrm{H} 4 B$ & 0.49 & 0.417 & $\mathrm{NH}_{2}(\mathrm{~N} 4)$ & -0.235 & -0.303 \\
\hline $\mathrm{H} 5 A$ & 0.471 & 0.424 & $\mathrm{NH}_{2}(\mathrm{~N} 5)$ & -0.231 & -0.244 \\
\hline $\mathrm{H} 5 B$ & 0.487 & 0.404 & $\mathrm{C} 4-\mathrm{N} 3-\mathrm{C} 3-\mathrm{N} 1$ & 0.579 & 0.862 \\
\hline
\end{tabular}

The dipole moment has been calculated for the metformin cation alone with the origin at the barycenter of protons (shown in Fig. S6). It was calculated with MoPro and results from the atomic spherical valence and dipole populations. The dipole moments from experiment (0.412D) and theory $(0.431 \mathrm{D})$ are in good accordance both in magnitude and direction.

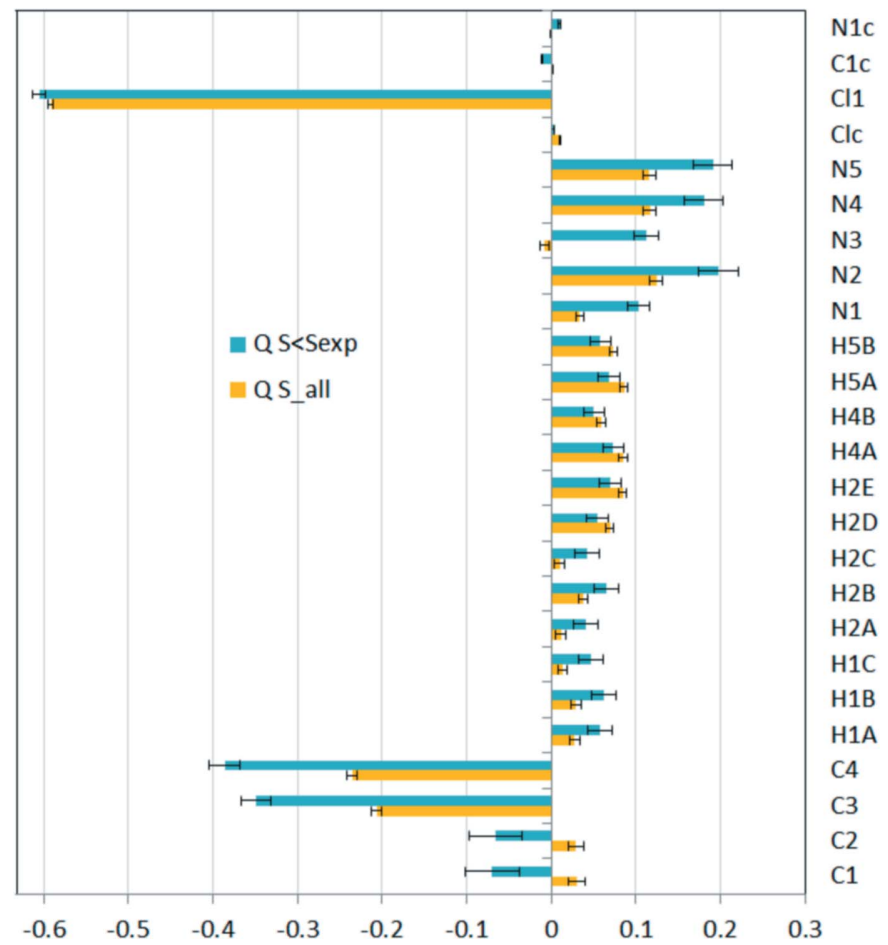

Figure 9

Atomic charges after refinement versus theoretical diffraction data. In orange, using all data up to $s=2.0 \AA^{-1}$; in blue, using data up to $s=$ $1.1115 \AA^{-1}$, which is the limit of experimental data. The standard deviations of the charges are shown as error bars. 
The effect of resolution cut-off on the refined valence populations was tested on the theoretical data which have been computed up to $s=2.0 \AA^{-1}$. An additional refinement was carried out using the same reciprocal resolution limit $s=$ $1.115 \AA^{-1}$ as the experimental diffraction data. The atomic charges $Q=N_{\text {val }}-P_{\text {val }}$ after the two refinements along with their standard deviations $\sigma$ are shown in Fig. 9. The charges of the $\mathrm{H}$ atoms and chloride anion are generally in good agreement between the two models within the standard uncertainty. In the THEO model with limited resolution, the $P_{\text {val }}-N_{\text {val }}$ charges are more positive for the $\mathrm{N}$ atoms and more negative for the $\mathrm{C}$ atoms and the differences between the two models can be significant, larger than $3 \sigma$. Fig. S7 shows the contraction/expansion $\kappa 1$ coefficients in the two models which show globally a high correlation (0.9912), but some differences are higher than $3 \sigma$. This illustrates that results of a charge density
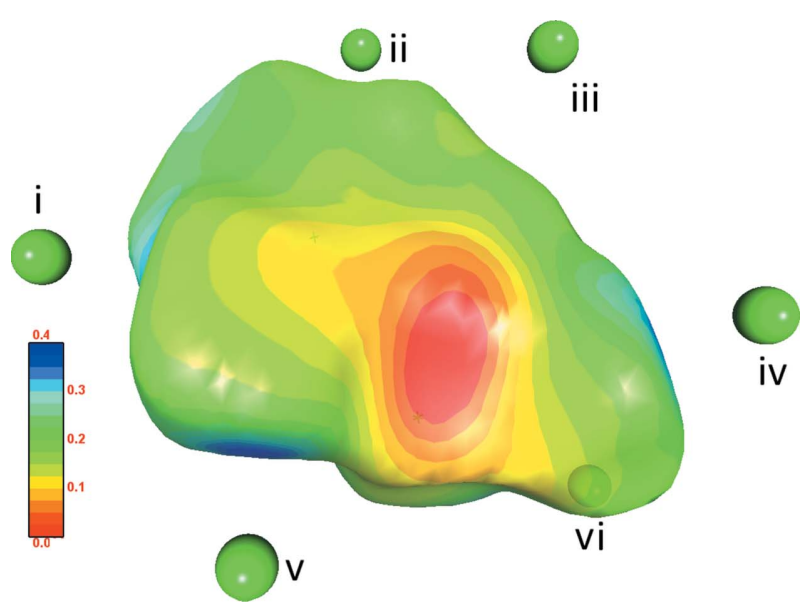

(a)
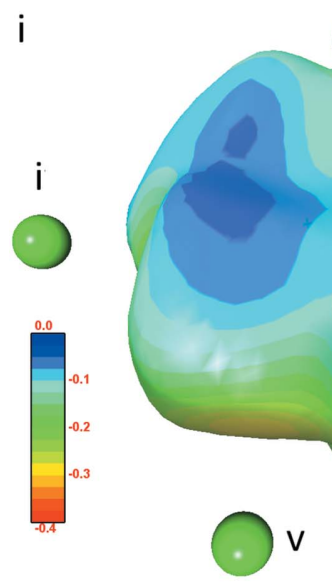

ii

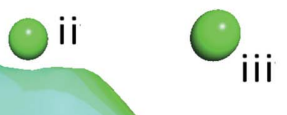

iii
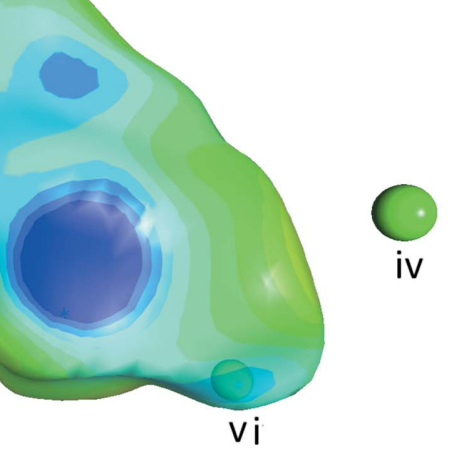

Figure 10

(b)

Electrostatic potential on the Hirshfeld surface of the metformin cation. The chloride atoms interacting with the metformin cation are shown. (a) Generated by the cation. (b) Generated by neighboring molecules in contact with the metformin cation. Contributing molecules: chloride $(x, y, z)$ and $17 \mathrm{MetCl}$ molecules around the central cation (list given in Table S6). The N3 atom with Lp is in front of the molecule. The closest interacting chloride anions are represented as green spheres and their symmetry number is given: (i) $x, y, z$; (ii) $-x, y+\frac{1}{2},-z+\frac{1}{2}$; (iii) $x,-y+\frac{1}{2}, z+\frac{1}{2}$; (iv) $-x+1, y+\frac{1}{2},-z+\frac{1}{2}$; (v) $-x+1,-y+1,-z+1$; (vi) $x+1,-y+, z+\frac{1}{2}$. refinement are dependent on resolution cut-offs even for theoretical data and would deserve to be further investigated.

\subsection{Electrostatic potential}

The molecular electrostatic potential (ESP) $V(\mathbf{r})$ is an inevitable property in order to understand molecular inter-

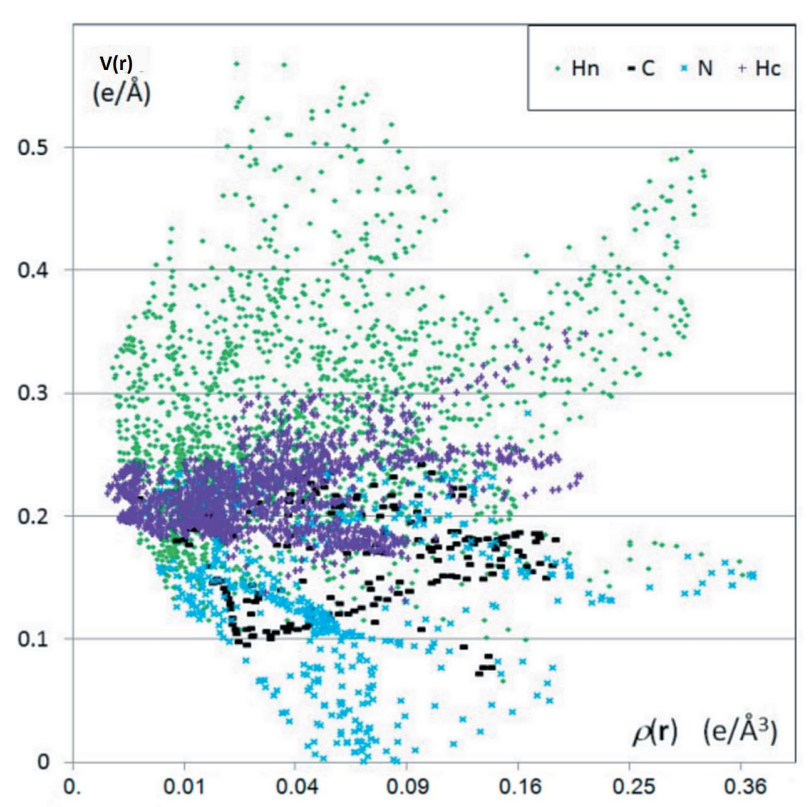

(a)

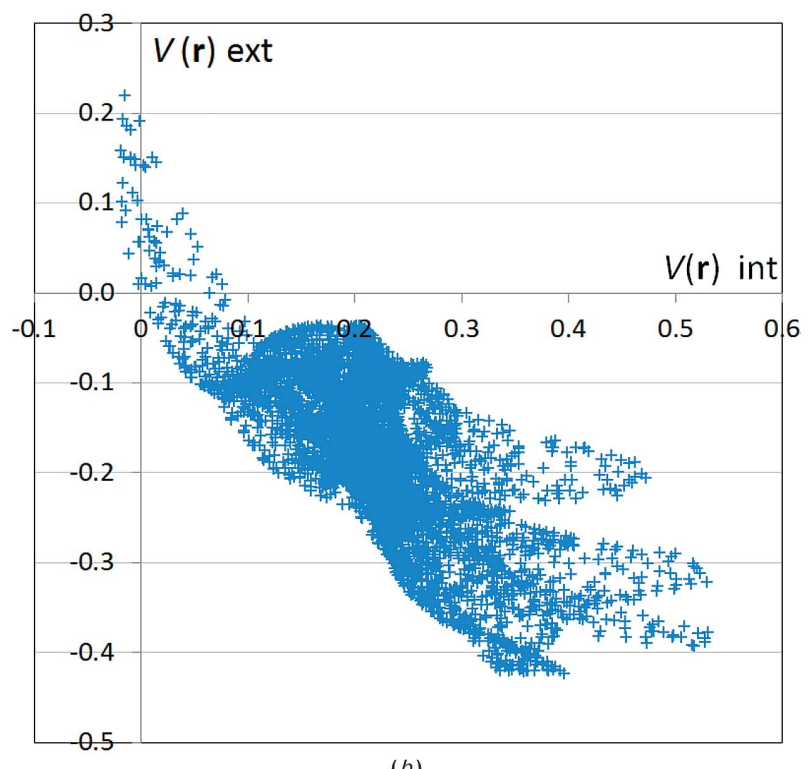

Figure 11

(a) Scatterplot of the electrostatic potential $V(\mathbf{r})$ generated by the cation versus total electron density $\rho(\mathbf{r})$ on the Hirshfeld surface around the metformin cation. Notice on the Hirshfeld surface $\rho_{\text {ext }}(\mathbf{r})=\rho_{\text {int }}(\mathbf{r})$. The color indicates the atom type $(\mathrm{Hn}, \mathrm{Hc}, \mathrm{C}, \mathrm{N})$ contributing most to the electron density on the surface. A square-root scale is used for $\rho(\mathbf{r})$. The $\rho(\mathbf{r})$ and $V(\mathbf{r})$ values on the Hirshfeld surface were retrieved with the software MoProViewer. (b) Scatterplot of the ESP $V_{\text {int }}(\mathbf{r})$ generated by the cation versus $V_{\mathrm{ext}}(\mathbf{r})$ generated by the chloride atom of the asymmetric unit plus 17 neighboring $\mathrm{MetCl}$ molecules. 
Table 8

The electrostatic energy $\left(\mathrm{kJ} \mathrm{mol}^{-1}\right)$ between interacting moieties cation $\cdots$ chloride (left) and cation...cation (right).

The contact atoms refer to the interactions with the smallest distance minus the sum of van der Waals radii $\left(d_{i j}-r_{i}-r_{j}\right)$. Symmetry operations apply to the second atom. Cation $\cdots$ cation contacts involving nonreciprocal symmetry operations $\left(\sigma \neq \sigma^{-1}\right)$ are not repeated. Involutional symmetry operations $\left(\sigma=\sigma^{-1}\right.$, marked $*$ ), which are inversions, should be counted as half for cation $\cdots$ cation interactions. For instance, the uncertainty for the interaction $\mathrm{H} 2 D \cdots \mathrm{Cl} 1$ (i) is s.s.d. $=20 \mathrm{~kJ} \mathrm{~mol}^{-1}$.

\begin{tabular}{llllll}
\hline Contact & Symmetry & $E_{\text {elec }}$ & Contact & Symmetry & $E_{\text {elec }}$ \\
\hline $\mathrm{C} 1 \cdots \mathrm{H} 2 D$ & $x, y, z$ & $-218(20)$ & $\mathrm{H} 1 A \cdots \mathrm{H} 1 C$ & $-x+1,-y+2,-z+1^{*}$ & $158(14)$ \\
$\mathrm{Cl} 1 \cdots \mathrm{H} 4 B$ & $x-1,-y+\frac{3}{2}, z-\frac{1}{2}$ & $-258(12)$ & $\mathrm{H} 2 B \cdots \mathrm{N} 4$ & $x-1, y, z-1$ & $134(10)$ \\
$\mathrm{C} 1 \cdots \mathrm{H} 4 A$ & $-x+1, y-\frac{1}{2},-z+\frac{3}{2}$ & $-191(11)$ & $\mathrm{C} 4 \cdots \mathrm{H} 2 C$ & $x+1,-y+\frac{3}{2}, z+\frac{1}{2}$ & $121(12)$ \\
$\mathrm{Cl} 1 \cdots \mathrm{H} 2 E$ & $-x+1,-y+1,-z+1$ & $-193(12)$ & $\mathrm{H} 4 A \cdots \mathrm{H} 4 B$ & $-x+2,-y+2,-z+2^{*}$ & $119(11)$ \\
$\mathrm{C} 1 \cdots \mathrm{H} 1 B$ & $-x, y-\frac{1}{2},-z+\frac{1}{2}$ & $-149(8)$ & $\mathrm{H} 1 B \cdots \mathrm{H} 5 B$ & $x-1, y, z$ & $114(11)$ \\
$\mathrm{Cl} 1 \cdots \mathrm{C} 1$ & $x,-y+\frac{3}{2}, z-\frac{1}{2}$ & $-169(19)$ & $\mathrm{H} 2 D \cdots \mathrm{H} 2 E$ & $-x+1,-y+1,-z+1 *$ & $110(12)$ \\
$\mathrm{C} 1 \cdots \mathrm{H} 4 B$ & $-x+1, y-\frac{1}{2},-z+\frac{3}{2}$ & $-259(11)$ & $\mathrm{N} 4 \cdots \mathrm{H} 2 B$ & $x+1, y, z+1$ & $106(10)$ \\
$\mathrm{Cl} 1 \cdots \mathrm{H} 5 B$ & $x+1, y-\frac{1}{2},-z+\frac{1}{2}$ & $-241(17)$ & $\mathrm{H} 2 E \cdots \mathrm{H} 4 A$ & $x,-y+\frac{3}{2}, z-\frac{1}{2}$ & $105(19)$ \\
Sum & & -1678 & $\mathrm{H} 5 A \cdots \mathrm{N} 3$ & $x,-y+\frac{3}{2}, z+\frac{1}{2}$ & $96(19)$ \\
\hline
\end{tabular}

negative $V(\mathbf{r})_{\text {int }}$ values around the cation, while the surrounding is locally electropositive.

Fig. 11(a) shows a scatterplot of electron density versus the electrostatic potential $V_{\text {int }}$ generated by the cation on the Hirshfeld surface of metformin. The points of high density highlight the strong contacts. Regions of high potential and electron density are found on the contact surface near the Hn atoms. A strong contact with low ESP is found around the N3 atom which has an electron Lp. The Hc atoms form weak hydrogen bonds with the chloride atom which correspond in the scatterplot to points of relatively high density $\left(0.20\right.$ e $\left.\AA^{-3}\right)$. Generally regions with high potential $V_{\text {int }}$ are found around Hn actions and to predict the chemically reactive nature of the molecule; electrophilic $(V>0)$ and nucleophilic $(V<0)$ regions of the molecule are highlighted. The Hirshfeld surface is colored in Fig. 10 according to the electrostatic potential $V(\mathbf{r})_{\text {int }}$ and $V(\mathbf{r})_{\text {ext }}$ generated by the cation molecule and the neighboring molecules, respectively. The ESP is calculated directly with the VMoPro tool from the Hansen \& Coppens equation describing the electron density ( $\mathrm{Su} \&$ Coppens, 1992). For the exterior ESP, the $\mathrm{Cl}^{-}$anion (symmetry $x, y, z$ ) and a cluster of surrounding $\mathrm{MetCl}$ molecules was at first generated and stored as a molecular file. The ESP potential generated by the metformin cation is, as expected, globally positive $\left\langle V(\mathbf{r})_{\text {int }}\right\rangle=+0.221$ with the root-mean-square devia-

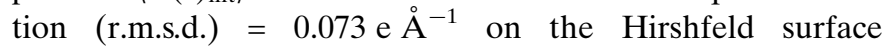
surrounding the molecule (Fig. 10a). The only region around the cation reaching a slightly negative potential is near the N3 atom which possesses an electron lone pair and is the only hydrogen bond acceptor site of metformin.

ESP can be mapped on Hirshfeld surfaces to provide direct insights into the electrostatic nature of the intermolecular interactions in crystals (Spackman et al., 2008. The ESP generated by the environment around the organic cation, namely the $\mathrm{Cl}^{-}$anion of the asymmetric unit and the surrounding $\mathrm{MetCl}$ molecules, is negative on the Hirshfeld

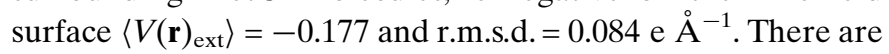
six chloride anions directly interacting with the cation and they are located near the electropositive regions $\left(\mathrm{NH}_{2}\right.$ groups) of the MetCl molecule. Globally, the inner and outer ESPs are positive and negative on the Hirshfeld surface (Fig. 11b). The two $V(\mathbf{r})$ potentials are negatively correlated $(c=-73 \%)$ on the surface confirming the high electrostatic complementarity of the cation and of its surroundings. The regions on the surface with highest $V(\mathbf{r})_{\text {int }}$ values around $0.5 \mathrm{e}^{-1}$ correspond globally to the most negative $V(\mathbf{r})_{\text {ext }}$ values around $-0.4 \mathrm{e} \AA^{-1}$ and are related to the $\mathrm{N}-\mathrm{H} \cdots \mathrm{Cl}^{-}$hydrogen bonds. On the other hand, the region of the N3 $\cdots \mathrm{H} 5 A-\mathrm{N} 5$ hydrogen bond is in a reverse situation with respect to the global ESP behavior: the N3 generates small positive and even atoms followed by $\mathrm{Hc}$ atoms. The surface around $\mathrm{N}$ atoms is found globally to be the most electronegative.

\subsection{Intermolecular interactions and electrostatic energy}

A calculation of the electrostatic energy between the neighboring molecules in the crystal has been carried out. The energy was computed between entities: cation...cation or cation... anion and are listed in Table 8 . The chloride/cation pairs have electrostatic energies in the range -149 to $-259 \mathrm{~kJ} \mathrm{~mol}^{-1}$. The topological properties of intermolecular contacts are given in Table S5. Among the hydrogen bonds, $\mathrm{Cl} 1 \cdots \mathrm{H} 4 \mathrm{~B}$ which exhibits the largest electron density at the $\mathrm{CP} \rho_{\mathrm{CP}}=0.115 \mathrm{e} \AA^{-3}$, is presumably the strongest hydrogen bond and corresponds to the dimer with the largest electrostatic energy.

The cation. - cation interactions have repulsive electrostatic energies between +96 and $+158 \mathrm{~kJ} \mathrm{~mol}^{-1}$. The cation dimer involving the strong hydrogen bond $\mathrm{N} 5-\mathrm{H} 5 A \cdots \mathrm{N} 3$ with the only acceptor on the cation has the least unfavorable electrostatic energy at $+96 \mathrm{~kJ} \mathrm{~mol}^{-1}$. The global electrostatic energy per metformin cation with its interacting neighbors is $-808 \mathrm{~kJ} \mathrm{~mol}^{-1}$. The crystal structure is held by the electrostatic attractive cation-anion interactions which are globally stronger than the cation-cation contacts. The latter unfavorable contacts are unavoidable in the $\mathrm{MetCl}$ crystal packing due to the much larger size of the cations compared with the anions.

\section{Conclusion}

In this study, we have presented a quantitative charge density study of the first-line anti-diabetic drug $\mathrm{MetCl}$ both from a high-resolution diffraction experiment at $100 \mathrm{~K}$ and corresponding periodic theoretical calculations obtained from theoretical structure factors, using the B3LYP/6-311G** level of theory. Using Bader's 'Atoms In Molecules theory' (Bader, 1990), the refined charge density has been analyzed. The 
Hirshfeld surface analysis revealed that the weak $\mathrm{H} \cdots \mathrm{H}$ contacts are the prime contributors to the crystal packing in terms of surface area $(54.3 \%)$. The enrichment ratio descriptor highlights that the $\mathrm{Hn} \cdots \mathrm{Cl}$ ionic bridges $(E=2.32)$ are the most favored contacts and are the driving force in the crystal packing formation. In addition, there is a strong $\mathrm{N}-$ $\mathrm{H} \cdots \mathrm{N}$ hydrogen bond involving the $\mathrm{N} 3$ atom which has an electron lone pair and displays negative ESP.

The topological analysis ensures the occurrence of $\pi$ delocalization of all the $\mathrm{C}-\mathrm{N}$ bonds except $\mathrm{C} 1-\mathrm{N} 1$ and $\mathrm{C} 2-$ $\mathrm{N} 1$ bonds involving methyl groups, denoting their partial double bond nature which is further supported by the bondorder index calculation. The topological bond-order analysis stresses that the $\mathrm{C} 4-\mathrm{N} 3$ bond is the strongest among $\mathrm{C}-\mathrm{N}$ bonds and has the highest bond-order value (1.44) and the highest electron density and Laplacian values. All the $\mathrm{N}$ atoms have a trigonal geometry and show three valence-shell charge concentrations on their bonds, except N3 which has only one prominent VSCC on its lone pair. Notably, the two electrondonating methyl groups as well as the $\mathrm{C} 3$ and $\mathrm{C} 4$ atoms possess the responsibility for the cationic character of metformin. The $\mathrm{C} 4-\mathrm{N} 4$ bond is more polarized as it involves the most positive $\mathrm{C} 4(1.291 \mathrm{e})$ atom and the most negative N4 $(-1.193 \mathrm{e})$ atom.

The ESP generated by the metformin cation is electropositive on the whole Hirshfeld surface except around the N3 atom possessing an electron Lp. Oppositely, the ESP generated by the cation surrounding molecules is electronegative on the surface, except around the $\mathrm{NH}_{2}$ group hydrogen bonded to N3. The inner and outer ESPs generated on the metformin cation Hirshfeld surface show a high complementarity.

\section{Related literature}

References cited in the supporting information include: Angyan (2000), Angyan et al. (1994), Bridgeman et al. (2001), Borisova \& Semenov (1973), Glendening \& Weinhold (1998), Howard \& Lamarche (2003), Mayer (1983, 1986), Raczynska (2010), Reed \& Schleyer (1990).

\section{Acknowledgements}

This work was granted access to the HPC resources of CINES/ CEA CCRT/IDRIS under the allocation x2016087449 made by GENCI. The authors SI and RN thank Professor T. N. G. Row, Solid State Chemistry Unit, Indian Institute of Science, Bangalore, India for the high-resolution X-ray intensity data collection and are grateful for the grant provided by University Grants Commission, India, in the form of Major Research Project [F.No. 41-848/2012(SR)]. The authors are grateful to the principal and secretary and the head of PG Physics Department of The American College, Madurai, India, for their continued encouragement and support during the progress of this work.

\section{References}

Allen, F. H. \& Bruno, I. J. (2010). Acta Cryst. B66, 380-386.
Allen, F. H., Kennard, O., Watson, D. G., Brammer, L., Orpen, A. G. \& Taylor, T. (1987). J. Chem. Soc. Perkin Trans. 2, p. S1.

Angyan, J. (2000). J. Mol. Struct. (Theochem.) 501-502, 379-388.

Angyan, J., Loos, M. \& Mayer, I. (1994). J. Phys. Chem. 98, 52445248.

Apra, E., Causa, M., Prencipe, M., Dovesi, R. \& Saunders, V. R. (1993). J. Phys. Condens. Matter, 5, 2969-2976.

Bader, R. F. W. (1990). Atoms in Molecules: A Quantum Theory. Oxford University Press.

Becker, P. J. \& Coppens, P. (1974). Acta Cryst. A30, 129-147.

Benabicha, F., Pichon-Pesme, V., Jelsch, C., Lecomte, C. \& Khmou, A. (2000). Acta Cryst. B56, 155-165.

Bennett, W. L., Wilson, L. M., Bolen, S. S., Nisha, M., Sonal, S., Ranee, C., Marinopoulos, S. S., Puhan, M. A., Ranasinghe, P., Nicholson, W. K., Block, L., Odelola, O., Dalal, D. S., Ogbeche, G. E., Chandrasekar, A., Hutfless, S., Bass, E. B. \& Segal, J. B. (2011). Oral Diabetes Medications for Adults With Type 2 Diabetes: An Update. Comparative Effectiveness Review No. 27. Publication No. 11EHC038-EF.

Blessing, R. H. (1997). J. Appl. Cryst. 30, 421-426.

Borisova, N. P. \& Semenov, S. G. (1973). Vestn. Leningrad University, pp. 119-124.

Bridgeman, A. J., Cavigliasso, G., Ireland, L. R. \& Rothery, J. (2001). J. Chem. Soc. Dalton Trans. pp. 2095-2108.

Bruker AXS (2012). PROTEUM2, Version 2012.2. Bruker AXS Inc., Madison, Wisconsin, USA.

Chęcińska, L., Grabowsky, S., Małecka, M., Rybarczyk-Pirek, A. J., Jóźwiak, A., Paulmann, C. \& Luger, P. (2011). Acta Cryst. B67, 569581.

Childs, S. L., Chyall, L. J., Dunlap, J. T., Coates, D. A., Stahly, B. C. \& Stahly, G. P. (2004). Cryst. Growth Des. 4, 441-449.

Cosier, J. \& Glazer, A. M. (1986). J. Appl. Cryst. 19, 105-107.

Costa, P. \& Lobo Eur, J. M. (2001). J. Pharm. Sc. 13, 123-133.

Cutler, E. D.\& Prescott, P. (2006). Diabetes: Treatment Options Report (April 2006). Reports prepared for the California HealthCare Foundation; http:www.chcf.org.

Dolomanov, O. V., Bourhis, L. J., Gildea, R. J., Howard, J. A. K. \& Puschmann, H. (2009). J. Appl. Cryst. 42, 339-341.

Domagała, S. \& Jelsch, C. (2008). J. Appl. Cryst. 41, 1140-1149.

Dovesi, R., Orlando, R., Erba, A., Zicovich-Wilson, C. M., Civalleri, B., Casassa, S., Maschio, L., Ferrabone, M., De La Pierre, M., D’Arco, P., Noël, Y., Causà, M., Rérat, M. \& Kirtman, B. (2014). Int. J. Quantum Chem. 114, 1287-1317.

Farrugia, L. J. \& Senn, H. M. (2012). J. Phys. Chem. A, 116, 738-746.

Frisch, M. J. et al. (2009). GAUSSIAN. Gaussian, Inc., Wallingford CT, USA.

Glendening, E. D. \& Weinhold, F. (1998). J. Comput. Chem. 19, 610627.

Glendening, E. D., Badenhoop, J. K., Reed, A. E., Carpenter, J. E., Bohmann, J. A., Morales, C. M., Landis, C. R. \& Weinhold, F. (2013). Theoretical Chemistry Institute, University of Wisconsin, Madison, WI, USA; http://nbo6.Chem.wisc.edu/.

Grimme, S. (2006). J. Comput. Chem. 27, 1787-1799.

Guillot, B. (2012). Acta Cryst. A68, s204.

Hansen, N. K. \& Coppens, P. (1978). Acta Cryst. A34, 909-921.

Hariharan, M., Rajan, S. S. \& Srinivasan, R. (1989). Acta Cryst. C45, 911-913.

Herrnstadt, C., Mootz, D., Wunderlich, H. \& Möhrle, H. (1979). J. Chem. Soc. Perkin Trans. 2, pp. 735-740.

Howard, S. T. \& Lamarche, O. (2003). J. Phys. Org. Chem. 16, $133-$ 141.

Jelsch, C., Ejsmont, K. \& Huder, L. (2014). IUCrJ, 1, 119-128.

Jelsch, C., Guillot, B., Lagoutte, A. \& Lecomte, C. (2005). J. Appl. Cryst. 38, 38-54.

Jelsch, C. et al. (2017). In preparation.

Laar, F. A. van de (2008). Vascular Health and Risk Management, 4, 1189-1195.

Madsen, A. Ø. (2006). J. Appl. Cryst. 39, 757-758. 
Matta, C. F., Hernández-Trujillo, J., Tang, T. H. \& Bader, R. F. (2003). Chem. Eur. J. 9, 1940-1951.

Mayer, I. (1983). Chem. Phys. Lett. 97, 270-274.

Mayer, I. (1986). Int. J. Quant. Chem. 29, 477-483.

Mayer, I., Knapp-Mohammady, M. \& Suhai, S. (2004). Chem. Phys. Lett. 389, 34-38.

McKinnon, J. J., Spackman, M. A. \& Mitchell, A. S. (2004). Acta Cryst. B60, 627-668.

Meier, C., Kraenzlin, M. E., Bodmer, M., Jick, S. S., Jick, H. \& Meier, C. R. (2008). Arch. Intern. Med. 168, 820-825.

Melchior, W. R. \& Jaber, L. A. (1996). Ann. Pharmacother. 30, 158164.

Morrison, R. T. \& Boyd, R. N. (1973). Organic Chemistry, 3rd ed. Boston, USA: Allyn and Bacon Inc.

Mujika, J. I., Matxain, J. M., Eriksson, L. A. \& Lopez, X. (2006). Chem. Eur. J. 12, 7215-7224.

Niepötter, B., Herbst-Irmer, R. \& Stalke, D. (2015). J. Appl. Cryst. 48, 1485-1497.

Overgaard, J., Jones, C., Dange, D. \& Platts, J. A. (2011). Inorg. Chem. 50, 8418-8426.

Prince, E. (2004). Editor. International Tables for Crystallography, Vol. C. Dordrecht: Kluwer Academic Publishers.

Raczynska, D., Hallman, M., Kolczynska, K. \& Stepniewski, M. (2010). Symmetry, 2, 1485-1509.

Rajalakshmi, G., Hathwar, V. R. \& Kumaradhas, P. (2014). Acta Cryst. B70, 568-579.

Reed, A. E. \& Schleyer, P.V. R. (1990). J. Am. Chem. Soc. 112, 1434 1445.

Ripsin, C. M., Kang, H. \& Urban, R. J. (2009). Am. Fam. Physician, 79, 29-36.
Risérus, U., Willett, W. C. \& Hu, F. B. (2009). Prog. Lipid Res. 48, 4451.

Satyanarayana, T., Rajitha, V., Kumar, P. S., Ravinder, K., Shaji, G. \& Saranya, P. (2012). Der pharmaciasinica, 3, 58-63.

Selvin, E., Bolen, S., Yeh, H. C., Wiley, C., Wilson, L. M., Marinopoulos, S. S., Feldman, L., Vassy, J., Wilson, R., Bass, E. B. \& Brancati, F. L. (2008). Arch. Intern. Med. 168, 20702080.

Shaw, R. J., Lamina, K. A., Vasquez, D., Koo, S. H., Bardeesy, N., Depinho, R. A., Montminy, M. \& Cantley, L. C. (2005). Science, 310, 1642-1646.

Sheldrick, G. M. (2008). Acta Cryst. A64, 112-122.

Spackman, M. A. (2002). Z. Kristallogr. 217, 369-370.

Spackman, M. A. \& Byrom, P. G. (1997). Chem. Phys. Lett. 267, 215220.

Spackman, M. A., McKinnon, J. J. \& Jayatilaka, D. (2008). CrystEngComm, 10, 377-388.

Stepensky, D., Friedman, M., Srour, W., Raz, I. \& Hoffman, A. (2001). J. Controlled Release, 71, 107-115.

Stephen, A. D., Thomas, R., Srinivasan, P., Vijayan, N. \& Kumaradhas, P. (2011). J. Mol. Struct. 989, 122-130.

Stevens, R. (2014). Metformin Best for Type 2 Diabetes First Treatment, WebMD News from healthDay, Health Day Reporter. Stewart, W. S. \& Siddall, T. H. (1970). Chem. Rev. 70, 517551.

Su, Z. \& Coppens, P. (1992). Acta Cryst. A48, 188-197.

Su, Z. \& Coppens, P. (1997). Acta Cryst. A53, 749-762.

Venkateswara Rao, T., Bhadramma, N., Raghukiran, C. V. S. \& Madubabu, K. (2013). Ind. J. Res. Pharm. Braoiotech. 1, 893897. 